\title{
Caracterización geoquímica, petrográfica y evolución magmática del Campo Volcánico de Los Azufres, Michoacán, durante el Pleistoceno
}

\section{José Luis Arce ${ }^{1, *}$, Elizabeth Rangel ${ }^{2}$, Gabriel Valdez-Moreno ${ }^{3}$, Ricardo Saucedo ${ }^{4}$, Renato Castro-Govea ${ }^{5}$ y José Luis Macías ${ }^{6}$}

\author{
${ }^{1}$ Instituto de Geología, Universidad Nacional Autónoma de México, Cd. Universitaria, \\ Coyoacán 04510, Ciudad de México, México. \\ ${ }^{2}$ Posgrado en Ciencias de la Tierra, Universidad Nacional Autónoma de México, Cd. Universitaria, \\ Coyoacán 04510, Ciudad de México, México. \\ ${ }^{3}$ Unidad Académica de Ciencias de la Tierra, Universidad Autónoma de Guerrero, \\ Ex-Hacienda de San Juan Bautista S/N, Taxco El Viejo, Guerrero, México. \\ ${ }^{4}$ Instituto de Geología, Universidad Autónoma de San Luis Potosí, San Luis Potosí, México. \\ ${ }^{5}$ Instituto Mexicano del Petróleo, Eje Central Lázaro Cárdenas Norte 152, San Bartolo Atepehuacan, \\ Gustavo A. Madero, 07730, Ciudad de México, México. \\ ${ }^{6}$ Instituto de Geofísica, Universidad Nacional Autónoma de México, Ex-Hacienda de San José de la Huerta \#8701, \\ 58190, Morelia, Michoacán, México. \\ *jlarce@geologia.unam.mx
}

\section{RESUMEN}

El Campo Volcánico de Los Azufres alberga el segundo campo geotérmico más importante de México. La actividad volcánica en este campo inició hace aproximadamente $1.57 \mathrm{Ma}$ y se mantuvo activa hasta $<26 \mathrm{ka}$, con la emisión de productos de composición muy variada. La actividad volcánica ha generado flujos y mesas de lava, domos y estratovolcanes, muchos de ellos con depósitos piroclásticos asociados. La composición química de los productos de todas estas rocas permitió agruparlas en cuatro diferentes unidades: AndesíticoBasáltica, Andesítica, Dacítica y Riolítica. Los productos riolíticos son los más abundantes, con edades que van desde $1.5 \mathrm{Ma} a<26 \mathrm{ka}$, mientras que las unidades máficas oscilan entre 1.5 a $0.33 \mathrm{Ma}$. La mineralogía de las diferentes unidades es acorde con su composición química, la Unidad Andesítico-Basáltica contiene ol+plg+opx+cpx y óxidos, la Unidad Andesítica contiene plg+opx+óxidos, la Unidad Dacítica contiene plg+opx+cpx+anf+bt y óxidos, así como trazas de cuarzo y circón, y la Unidad Riolítica contiene qz+sanidino+plg+bt+anf y óxidos. En general, las concentraciones de elementos mayores de las muestras analizadas de todas las unidades muestran características evolutivas claras que sugieren una relación genética, con un cambio en la tendencia definida por los datos químicos, aproximadamente a 64 $\%$ en peso de $\mathrm{SiO}_{2}$ para la mayoría de los elementos, lo que sugiere el fraccionamiento de fases minerales máficas. En cuanto a los elementos traza, se aprecian enriquecimientos en elementos incompatibles y tierras raras ligeras, con anomalías positivas pronunciadas en $\mathrm{Pb}, \mathrm{U}$ y $\mathrm{K}$ y negativas en $\mathrm{Nb}$, Ta y Ti, además de una variación en la anomalía negativa de Eu con la composición. De acuerdo con el modelo petrogenético generado en este trabajo, el mecanismo principal de evolución responsable de la diversidad magmática en el CVLA fue la asimilación-cristalización fraccionada (AFC) de rocas corticales, de composición similar a la de los intrusivos de La Huacana, con un coeficiente de masa asimilada/masa cristalizada de 0.5 , un valor de cristalización de $54 \%$, asumiendo el fraccionamiento de $5 \%$ de olivino, $15 \%$ de ortopiroxeno, $10 \%$ de plagioclasa y $5 \%$ de feldespato potásico. En menor medida, la asimilación simple sin cristalización fraccionada, también tuvo un papel en la evolución de los magmas, sin embargo, el modelo no explica la generación de los magmas más riolíticos del área, para los cuales seguramente actuó otro mecanismo que no se aprecia en el modelo y por lo tanto no se discute en este trabajo.

Palabras clave: Campo Volcánico Los Azufres; evolución magmática; asimilación combinada con cristalización fraccionada; vulcanismo calcialcalino; México.

\begin{abstract}
Los Azufres Volcanic Field hosts the second most important geothermal field in Mexico. Volcanic activity in this field began some $1.57 \mathrm{Ma}$ and lasted until $<26 \mathrm{ka}$, with the emission of different volcanic products with compositions varying from basaltic andesite to rhyolite. The volcanic products generated by this chemically heterogeneous activity are lava plateaus, domes, and stratovolcanoes, many of them with pyroclastic deposits associated. All these rocks were grouped into four different units: Basaltic-Andesite, Andesitic, Dacitic and Rhyolitic. The rhyolitic products are the most abundant with ages ranging from $1.5 \mathrm{Ma}$ to $<26 \mathrm{ka}$, whereas the mafic units vary from 1.5 to $0.33 \mathrm{Ma}$. The mineralogy observed in the different units is consistent with their chemical composition, the Basaltic-Andesite Unit contains ol $+p l g+o p x+c p x$ and oxides, while the Andesitic Unit contains plg+opx+oxides, the Dacitic Unit contains
\end{abstract}


$p l g+o p x+c p x+a n f+b t$ and oxides, as well as traces of quartz and zircon, whereas the Rhyolitic Unit contains qz+sanidine+plg+bt+anf and oxides. In general, the major element concentrations of all the analyzed samples display clear evolutive trends, which suggest a genetic relationship, with a break in slope configured by the geochemical data at approximately 64 $w t . \% \mathrm{SiO}_{2}$ for most elements that can be related to the fractionation of mafic mineral phases. Regarding trace elements, there is an enrichment in incompatible and light rare earth elements, with pronounced positive anomalies in $\mathrm{Pb}, \mathrm{U}$ and $\mathrm{K}$ and negative in $\mathrm{Nb}, \mathrm{Ta}$, and $\mathrm{Ti}$, in addition to a variable negative Eu anomaly depending on the chemical composition. According to our petrogenetic model generated in this work, the main evolutive mechanism responsible for the magmatic diversity in the CVLA was the assimilation of crustal rocks, with composition like that of La Huacana intrusive rocks, coupled with fractional crystallization (AFC). The results show an assimilated mass/crystallized mass ratio of 0.5 , crystallizing $54 \%$ of the magma, assuming the fractionation of $5 \%$ olivine, $10 \%$ clinopyroxene, $10 \%$ orthopyroxene, $20 \%$ plagioclase, $5 \%$ amphibole and $5 \%$ magnetite. To a lesser extent, assimilation without fractional crystallization also played a role in the magmatic evolution, although the model does not explain the generation of most rhyolitic magmas in the area, which were most likely derived by a different mechanism not discussed here.
Key words: Los Azufres Volcanic Field; magmatic evolution; assimilationfractional crystallization; calc-alkaline volcanism; Mexico.

\section{INTRODUCCIÓN}

El Campo Volcánico de Los Azufres (CVLA), localizado en el centro de México (Figura 1), está conformado por un conjunto de estructuras volcánicas de composición dominantemente riolítica, con algunos productos andesítico basálticos, andesíticos y dacíticos subordinados (Demant et al., 1975; Camacho, 1979; Camacho y Palacios, 1979; Garfias y González, 1978; Aumento y Gutiérrez, 1980; Macías et al., 2008; Arce et al., 2012; Rangel et al., 2018). Esta gran diversidad composicional sugiere procesos diversos de evolución magmática, como por ejemplo cristalización fraccionada, asimilación cortical, mezcla de magmas, anatexis, entre otros (Fowler et al., 2004). Estudios previos basados en el análisis petrográfico y geoquímico de elementos mayores en roca total, han atribuido la variación composicional del CVLA a la diferenciación de magmas máficos en una cámara magmática periódicamente reabastecida, propiciando a su vez procesos de mezcla de magmas que dieron lugar a magmas dacíticos (Demant, 1981; Cathelineau et al., 1987; 1991; Ferrari et al., 1991; Pradal y Robin,

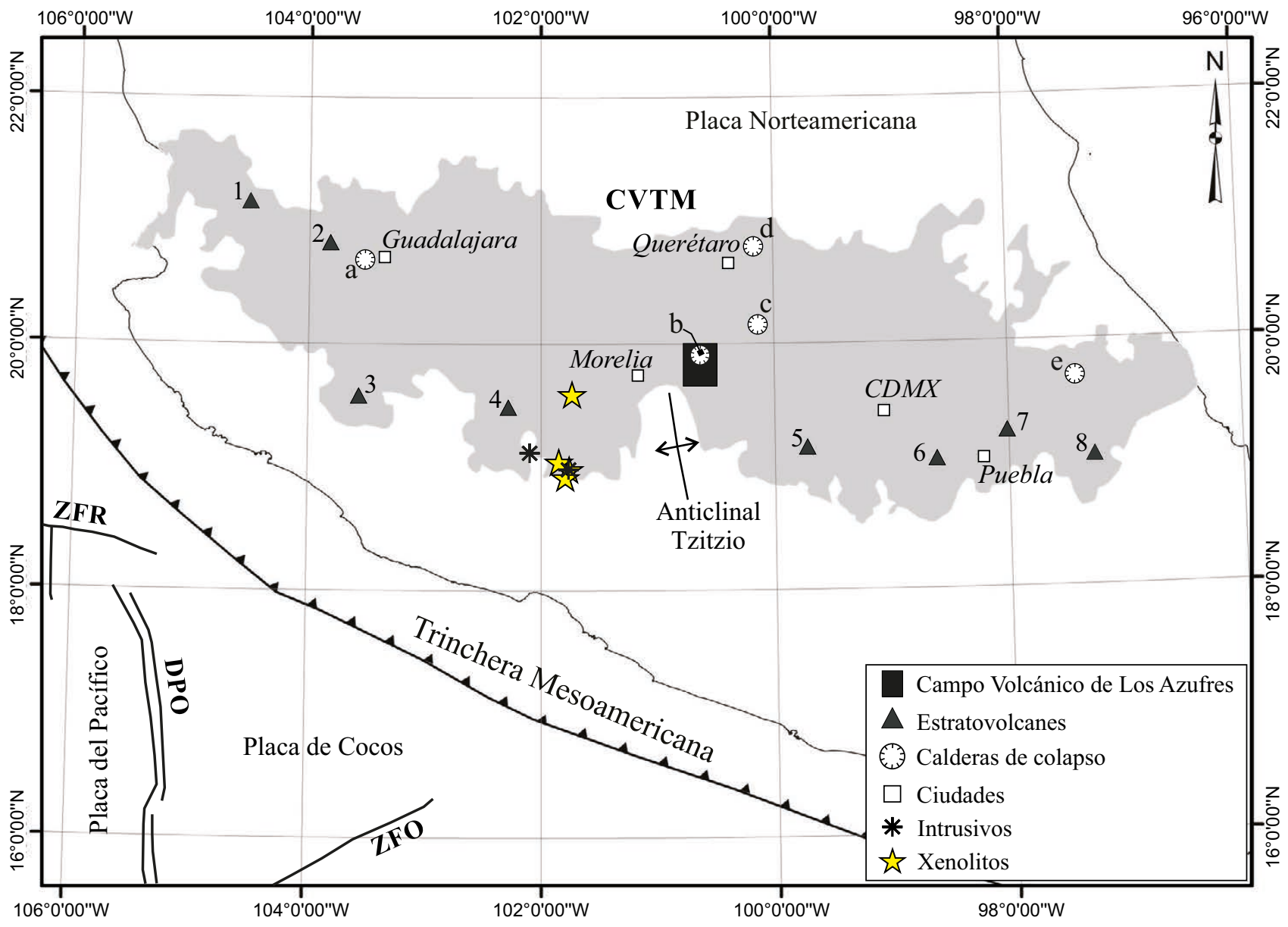

Figura 1. Mapa del centro de México con rasgos tectónicos, así como la ubicación del Campo Volcánico de Los Azufres dentro del Cinturón Volcánico Transmexicano (CVTM), muestras de los intrusivos de La Huacana, Michoacán (Ortega-Gutiérrez et al., 2014) y de los xenolitos graníticos, granodioríticos y dioríticos, encontrados dentro de los productos de los volcanes Jorullo y Arócutin (Corona-Chávez et al., 2006; Rasoazanamparany et al., 2016). Estructuras volcánicas: 1 = Ceboruco; 2 = Tequila; 3 = Volcán de Colima; 4 = Tancítaro; 5 = Nevado de Toluca; 6 = Popocatépetl; 7 = La Malinche; $8=$ Pico de Orizaba; $\mathrm{y}$ calderas volcánicas de colapso: $\mathrm{a}=$ La Primavera; $\mathrm{b}=$ Los Azufres; $\mathrm{c}=$ Amealco; $\mathrm{d}=$ Amazcala; $\mathrm{e}=$ Los Humeros. $\mathrm{ZRF}=\mathrm{Zona}$ de fractura Rivera; $\mathrm{DPO}=$ Dorsal del Pacífico Oriental; ZFO = Zona de fractura Orozco. 
1994). No obstante, llama la atención que la mayoría de las rocas del CVLA sea de composición riolítica y con un amplio intervalo temporal (> 1.5 Ma a Pleistoceno tardío; Macías et al., 2008; Arce et al., 2012; Rangel et al., 2018), donde incluso se traslapa con las edades de las andesitas basálticas, andesitas y dacitas.

Esta composición heterogénea, en un período de tiempo relativamente corto $(1.57 \mathrm{Ma})$, con productos volcánicos tanto efusivos como explosivos sugieren procesos complejos de evolución magmática. Mediante el uso de observaciones petrográficas y análisis químicos de roca total, combinada con información de trabajo de campo y geocronológica, en el presente trabajo se discuten el o los mecanismos de evolución magmática que han generado la diversidad composicional en el CVLA. Los resultados ayudarán a comprender la heterogeneidad magmática, así como su presencia en el vulcanismo monogenético que se aprecia alrededor del CVLA. Cabe destacar que la explotación del yacimiento geotérmico ocurre en una zona de domos riolíticos, por lo tanto, es indispensable realizar investigaciones más precisas sobre estos productos félsicos y su relación con el potencial geotérmico de la zona.

\section{Estudios previos}

El campo geotérmico de Los Azufres ocupa el segundo lugar en México en la producción de energía geotérmica, con una capacidad actual de 248 MW generada a partir de 40 pozos productores (Pérez-Esquivias et al., 2010; CeMIEGeo, 2018). Además, ha sido objeto de muchos estudios por parte de la Comisión Federal de Electricidad, cuyos resultados en su mayoría han sido publicados en reportes internos. Los primeros estudios geológicos regionales fueron desarrollados por Demant et al. (1975), Palacios y Camacho (1976), entre otros. Posteriormente, una serie de investigaciones petrológicas fueron publicadas (Silva-Mora, 1979; Aumento y Gutiérrez, 1980), así como estudios geofísicos y estructurales (Campos-Enríquez y Garduño-Monroy, 1995; De la Cruz et al., 1982; Garduño-Monroy y Martiñón-García, 1984).

En 1985, Dobson y Mahood realizaron estudios estratigráficos, donde definieron que la actividad de Los Azufres databa desde $1 \mathrm{Ma}$ y describieron tres secuencias silícicas: riodacitas Agua Fría (1.03-0.84 Ma), dacitas San Andrés (0.33 Ma) y riolitas Yerbabuena (0.30-0.15 Ma). Posteriormente, Pradal y Robin (1985) y Pradal (1990) propusieron que Los Azufres era el resultado de la resurgencia de una caldera de $18 \times 20 \mathrm{~km}$ de diámetro, originada durante el Pleistoceno. Garduño-Monroy (1987) describió a la Sierra de Santa Inés como el borde norte de dicha caldera, cuya actividad había expulsado una gran cantidad de ignimbritas durante el Plioceno, seguida por el emplazamiento de domos riolíticos. En este mismo tenor, Ferrari et al. (1991) propusieron la presencia de una caldera anidada de 20 $\times 15 \mathrm{~km}$ de diámetro, originada en el Mioceno y reactivada en el Plioceno, asociada con cuatro depósitos de ignimbrita. Un estudio más detallado de las secuencias volcánicas del CVLA fue realizado por Pradal y Robin (1994), en donde dividieron al vulcanismo en un primer periodo ( $1.5 \mathrm{a} 0.8 \mathrm{Ma})$ caracterizado por vulcanismo silícico, seguido de vulcanismo máfico, y un segundo periodo ( $\sim 0.6 \mathrm{Ma}$ a $26 \mathrm{ka})$ de vulcanismo máfico a silícico.

Recientemente, se realizó un estudio cartográfico, estratigráfico y estructural de la zona, apoyado en fechamientos isotópicos por el método ${ }^{40} \mathrm{Ar} /{ }^{39} \mathrm{Ar}$ y radiocarbono del área del campo geotérmico (Macías et al., 2008; Pérez-Esquivias et al., 2010). Este trabajo se realizó con el convenio de colaboración de la Gerencia de Proyectos Geotermoeléctricos de la CFE y el Instituto de Geofísica de la Universidad Nacional Autónoma de México (9400035204). Con estos trabajos se determinó que la actividad volcánica asociada al campo geotérmico de Los Azufres es del Pleistoceno y que está distribuida en todo el campo, incluyendo domos, estratovolcanes y volcanes monogenéticos, con erupciones tanto efusivas como explosivas de diversa índole que han generado gran diversidad de rocas volcánicas (flujos de lava, avalanchas de escombros y depósitos piroclásticos) de composición muy variada (andesitas basálticas a riolitas). De los trabajos más recientes resalta que el estratovolcán Guangoche, tuvo intensa actividad explosiva y efusiva con al menos tres erupciones plinianas-subplinianas fechadas entre 29 ka y <26 ka (Rangel, 2013; Rangel et al., 2018).

En estos últimos trabajos se descarta que el vulcanismo asociado al campo geotérmico de Los Azufres esté relacionado a la caldera propuesta en trabajos más antiguos, dado que los remanentes de la caldera mencionada por Garduño-Monroy (Sierra Santa Inés) tienen edades entre el Mioceno medio y Plioceno temprano, mientras que las edades más antiguas del Campo Volcánico de Los Azufres son de 1.57 Ma y tan recientes como < 26 ka (Arce et al., 2012; Rangel, 2013; Rangel et al., 2018). Estos últimos trabajos definen al CVLA como un complejo volcánico, constituido por 96 estructuras volcánicas de diversos tipos (estratovolcanes, domos, flujos de lava y depósitos piroclásticos), agrupadas en cuatro unidades litológicas principales con base en edad y composición química.

\section{MARCO GEOLÓGICO}

El Campo Volcánico de Los Azufres se localiza en la parte central del Cinturón Volcánico Transmexicano (CVTM), a $55 \mathrm{~km}$ al este de Morelia (Figura 1). El CVTM es un arco volcánico continental, orientado aproximadamente este-oeste, con más de $1000 \mathrm{~km}$ de longitud (Demant, 1978) y se extiende desde el Golfo de México hasta la costa del Pacífico (Figura 1). Este arco está relacionado con la subducción de las placas de Rivera y Cocos por debajo de la placa de Norteamérica (Pardo y Suárez, 1995; Ferrari et al., 1999; Gómez-Tuena et al., 2005) a través de la Trinchera Mesoamericana (Figura 1). Las estructuras volcánicas en este arco son diversas, incluyendo estratovolcanes, calderas, domos y campos monogenéticos, de composición muy variable (andesítico basáltico a riolítica) y con afinidades calcialcalinas, así como algunos ejemplos de vulcanismo alcalino (Aguirre-Díaz y López-Martínez, 2001; Aguirre-Díaz, 2003; Gómez-Tuena et al., 2005; Ferrari et al., 2012).

El Campo Volcánico de Los Azufres tiene como basamento a las rocas sedimentarias siliciclásticas del Triásico y del Cretácico tardío al Eoceno temprano (Figura. 2; Altamira-Areyán, 2002; Benammi et al., 2005; Mariscal-Ramos et al., 2005; Talavera-Mendoza et al., 2007; Centeno-García et al., 2008; Martini et al., 2009), que conforman el núcleo y flancos del anticlinal Tzitzio (Figura 1), ubicado a $25 \mathrm{~km}$ al suroeste del CVLA.

Las rocas triásicas, conocidas también con los nombres de Flysch Patámbaro (Pasquaré et al., 1991) y Sucesión Metamórfica Tzitzio (Martini et al., 2009), son una sucesión de lutitas y areniscas con metamorfismo de bajo grado (Talavera-Mendoza et al., 2007; Martini et al., 2009). Las rocas del Cretácico tardío-Eoceno temprano están conformadas por una sucesión de conglomerados, areniscas y lutitas, con intercalaciones de flujos de lava andesítica de la Formación Cutzamala (Altamira-Areyán, 2002; Martini et al., 2009). Estas rocas están cortadas por rocas intrusivas del Eoceno medio-tardío (Martini et al., 2009) (Figura 2), asociadas con los plutones de La Huacana (Martini et al., 2009), que afloran en los alrededores del pueblo del mismo nombre, en Michoacán.

Posteriormente ocurren secuencias volcánicas y sedimentos fluviolacustres que van del Mioceno temprano al Plioceno (Figura 2). La secuencia volcánica más antigua está representada por la Sierra de Mil Cumbres del Mioceno temprano (23-14 Ma; Macías et al., 2008; 


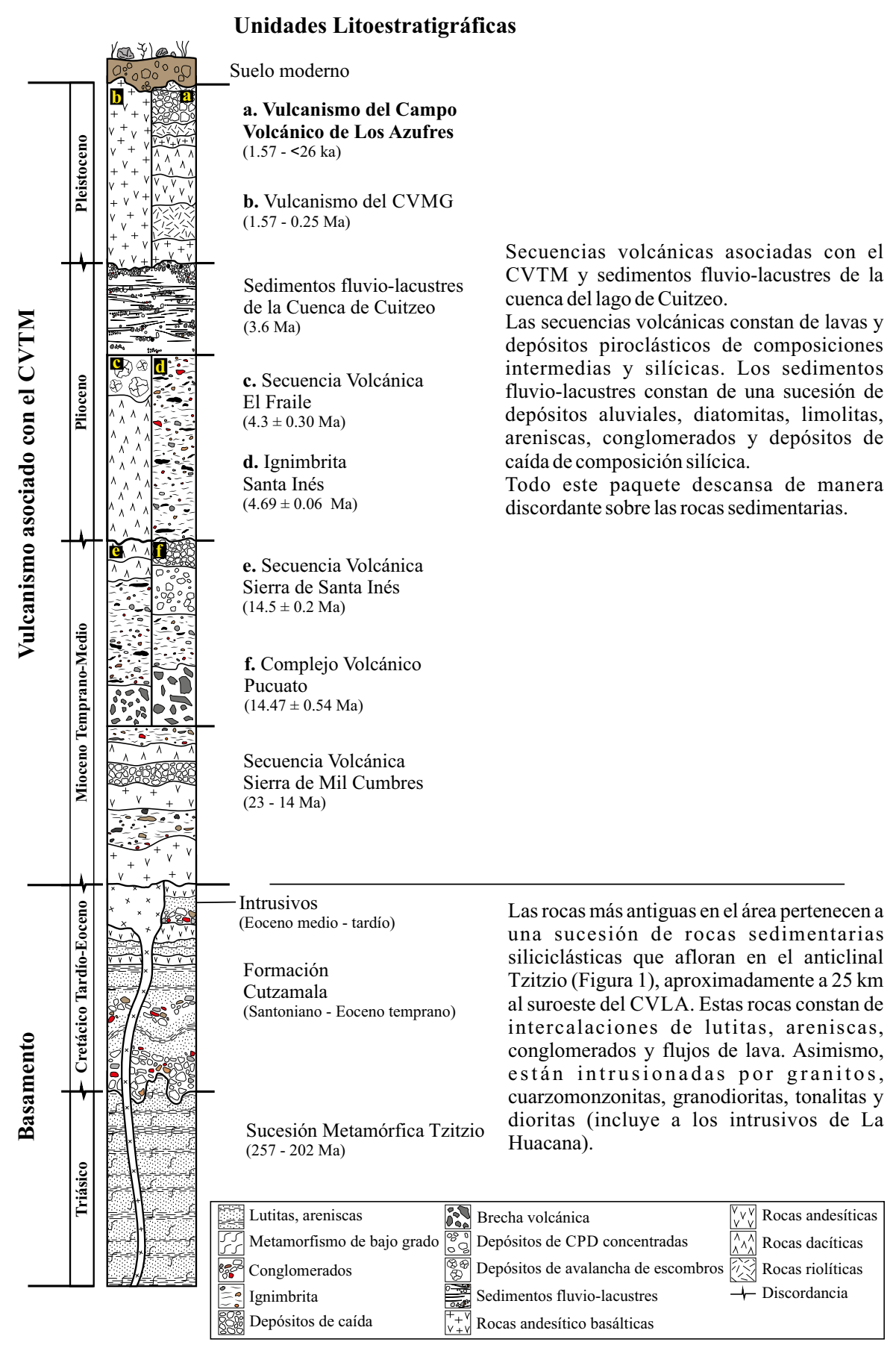

Figura 2. Columna estratigráfica regional del área del Campo Volcánico de Los Azufres (CVLA), con base en estudios previos mencionado en el texto. CVMG = Campo Volcánico Michoacán-Guanajuato; CVTM = Cinturón Volcánico Transmexicano; CPD = Corrientes piroclásticas de densidad. Ver texto para la referencia de las edades.

Arce et al., 2012; Gómez-Vasconcelos et al., 2015). Afloramientos de esta secuencia se encuentran al suroeste del CVLA (Figura 3) y son producto de la formación de varias estructuras caldéricas, que originaron secuencias piroclásticas complejas, intercaladas con flujos de lava de composición bimodal (máfica y silícica) (Gómez-Vasconcelos et al., 2015).

Cronológicamente más joven, se ubica el Complejo Volcánico Pucuato y la Secuencia Volcánica Sierra de Santa Inés (Figura 2) que afloran al sur y al norte del CVLA, respectivamente (Figura 3). El Complejo Volcánico Pucuato consta de brechas volcánicas andesí- ticas e ignimbritas, fechadas en $14.47 \pm 0.54 \mathrm{Ma}$ (Ferrari et al., 1991; Macías et al., 2008; Arce et al., 2012); mientras que la secuencia Santa Inés está representada por una estructura semicircular definida por Garduño-Monroy (1987) como el remanente norte de la caldera de Los Azufres. La Sierra de Santa Inés está constituida por una secuencia de ignimbritas y lavas andesíticas-dacíticas con edades que van de $14.5 \pm$ $0.2 \mathrm{Ma}$ en la base, hasta $4.69 \pm 0.06 \mathrm{Ma}$ para una ignimbrita que corona a dicha secuencia (Macías et al., 2008; Arce et al., 2012). Al sureste del CVLA se encuentra la Secuencia Volcánica El Fraile que consta de un complejo de domos endógenos de composición dacítica (fechados en 


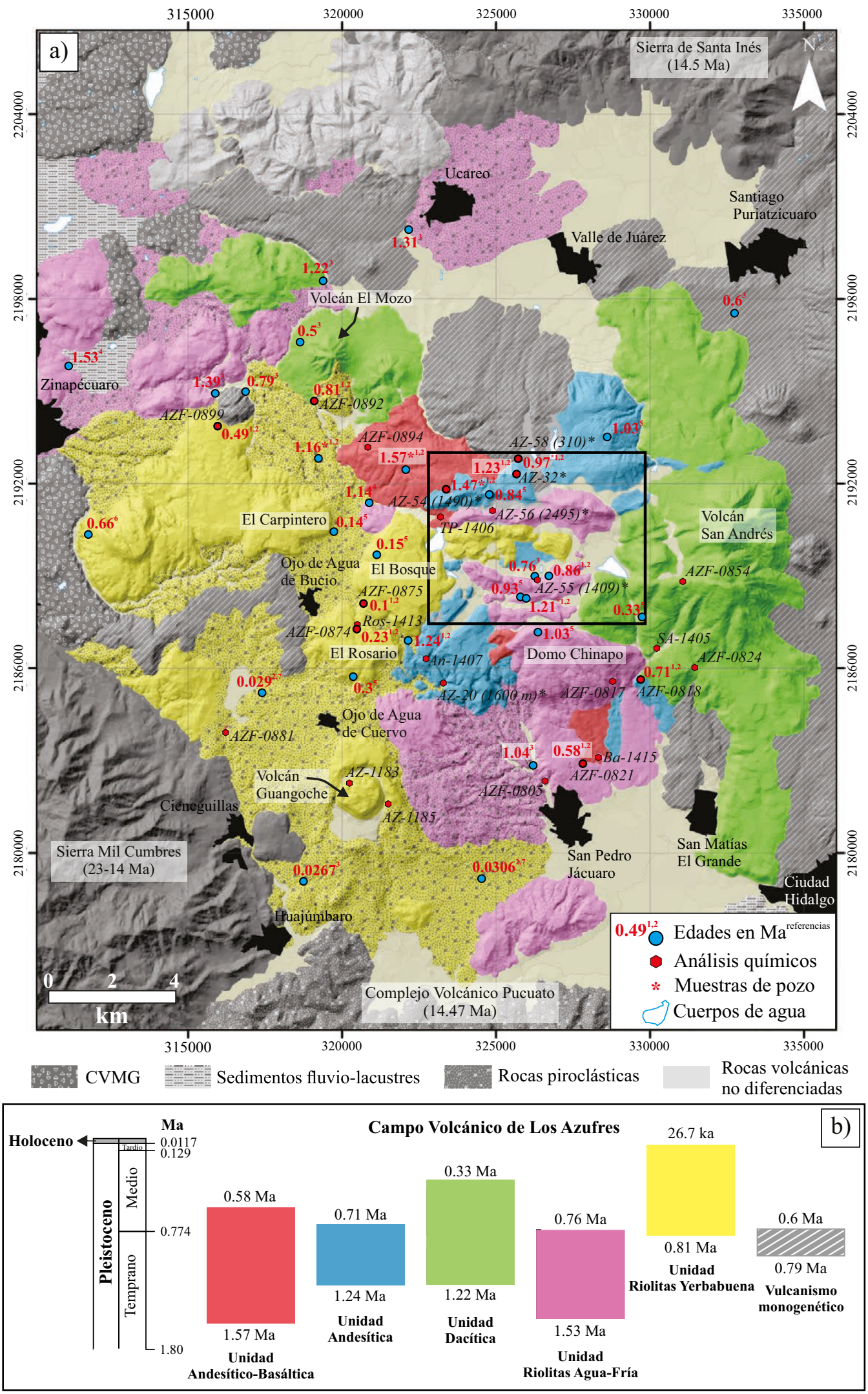

Figura 3. a) Mapa geológico del área del Campo Volcánico de Los Azufres (modificado de Macías et al., 2008 y Arce et al., 2012). Se resaltan las cuatro unidades mencionadas en el texto, así como la ubicación de las muestras referidas en las tablas 1 y 2 y algunas edades (en Ma). El recuadro negro enmarca la ubicación del campo geotérmico de Los Azufres. Referencias: 1 = Macías et al. (2008); 2 = Arce et al. (2012); 3 = Pradal y Robin (1994); $4=$ Ferrari et al. (1991); $5=$ Dobson y Mahood (1985); 6 = Gómez-Vasconcelos et al. (2020); 7 = Rangel (2013). b) Panel estratigráfico de las principales unidades que conforman al Campo Volcánico de Los Azufres. 
$4.3 \pm 0.30 \mathrm{Ma}$ ), así como de depósitos de avalancha de escombros (Ferrari et al., 1991; Pasquaré et al., 1991) (Figura 2). Al noroeste del CVLA están expuestos depósitos lacustres y fluvio-lacustres asociados a la cuenca del lago de Cuitzeo, fechados en $3.6 \mathrm{Ma}$ (Figuras 2 y 3; Israde-Alcántara y Garduño-Monroy, 1999; Israde-Alcántara et al., 2008, 2010).

Finalmente, se encuentran las rocas del Campo Volcánico de Los Azufres, representadas por una diversidad de tipos de estructuras volcánicas y litologías de distinta composición y edades que van de $1.57 \mathrm{Ma}$ hasta < 26 ka (Macías et al., 2008; Arce et al., 2012; Rangel, 2013), divididas en cuatro diferentes unidades con base en su composición química y mineralógica: 1. Unidad Andesítico-Basáltica, 2. Unidad Andesítica, 3. Unidad Dacítica y 4. Unidad Riolítica. Esta última subdividida en Riolitas Agua Fría y Riolitas Yerbabuena, como en los trabajos previos (Dobson y Mahood, 1985). Contemporáneamente, al este y dentro del CVLA, se encuentran productos de vulcanismo monogenético de composición dominantemente máfica y con edades de 0.79 a 0.6 Ma (Pradal y Robin, 1994) (Figura. 3), de los cuales no se tiene más información. También, al oeste y noroeste del CVLA se encuentran flujos de lava y conos de escoria asociados con el vulcanismo del Campo Volcánico Michoacán-Guanajuato (CVMG; Figura 3). Estas rocas tienen una composición andesítica basáltica y andesítica, y en el área de estudio se les ha asignado una edad de 1.57 a $0.25 \mathrm{Ma}$ (Figura 2; Macías et al., 2008; Arce et al., 2012; Gómez-Vasconcelos et al., 2020).

\section{UNIDADES VOLCÁNICAS Y MUESTREO}

La Unidad Andesítico-Basáltica aflora de manera restringida, representa las rocas más viejas del CVLA (1.57 a 0.58 Ma; Macías et al., 2008; Arce et al., 2012), compuesta por flujos de lava de composición andesítico-basáltica (ver sección de resultados), de color gris oscuro, de textura porfídica y afanítica, con fenocristales de plagioclasa + olivino + piroxeno. De esta unidad se obtuvieron cinco muestras de lava (Tabla 1) en las localidades de El Capulín, Rincón de Rubios y Tule-El Palmar (Figura 3).

La Unidad Andesítica (Figura 3) aflora en la parte central del CVLA y también se ha reportado en varios pozos perforados dentro del campo geotérmico. Esta unidad está constituida por flujos de lava de color gris claro de composiciones andesíticas a andesítico basálticas (ver la sección de resultados), comúnmente con juntas de enfriamiento. Las rocas exhiben textura porfídica con fenocristales de plagioclasa + piroxeno. La edad de esta unidad varía de 1.24 a $0.71 \mathrm{Ma}$ (Dobson y Mahood, 1985; Macías et al., 2008; Arce et al., 2012). De esta unidad se obtuvieron seis muestras de roca para análisis químicos (Tabla 1), de las cuales dos corresponden a muestras superficiales (Figura 3) y cinco pertenecen a muestras colectadas en pozos a diferentes profundidades (ver Tabla 1).

La Unidad Dacítica consta de diversas estructuras volcánicas (estratovolcanes y flujos de lava), incluyendo la dacita Tejamaniles, los volcanes El Mozo y San Andrés, y otras estructuras de la misma composición (Figura 3). Comúnmente estas rocas muestran estructura fluidal, con textura porfídica y una asociación mineralógica de fenocristales de plagioclasa + cuarzo + anfíbol + biotita y piroxeno. Las edades definidas para esta unidad varían de 1.22 a $0.33 \mathrm{Ma}$ (Pradal y Robin, 1994; Dobson y Mahood, 1985). Solo se obtuvieron tres muestras para análisis químicos (Tabla 1), todas corresponden al volcán San Andrés (Figura 3).

La Unidad Riolítica, subdividida en Riolitas Agua Fría, con edades de 1.53 a 0.76 Ma y Riolitas Yerbabuena con edades de $0.81 \mathrm{Ma}$ a $0.26 \mathrm{ka}$ (Dobson y Mahood, 1985; Ferrari et al., 1991; Pradal y Robin, 1994; Macías et al., 2008; Arce et al., 2012) (Figura 3). La subunidad Agua
Fría está constituida por domos y mesas de lava y flujos piroclásticos, todos de composición riolítica (ver sección de resultados), con textura porfídica y en ocasiones con texturas de desvitrificación. Algunos de los domos están fuertemente alterados, con desarrollo de caolín y precipitación de azufre, ya que se encuentran dentro del campo geotérmico (Figura 3). La asociación mineral está conformada por feldespato + cuarzo + biotita + anfíbol. Los depósitos piroclásticos están constituidos por fragmentos de pómez, obsidiana, así como por bloques densos de lava riolítica, inmersos en una matriz de ceniza fina, que afloran principalmente en las inmediaciones del poblado de San Pedro Jácuaro (Figura 3). De esta subunidad se colectaron dos muestras, una corresponde al Domo Chinapo (AZF-0817) y la otra a la secuencia piroclástica San Pedro Jácuaro (AZF-0805; Figura 3).

La subunidad Yerbabuena está constituida por domos y mesas de lava, el volcán Guangoche y varios depósitos piroclásticos (flujos piroclásticos y depósitos de caída de pómez), que afloran principalmente al NO, O, y SO del CVLA (Figura 3). En general, las lavas presentan textura porfídica, con fenocristales de feldespato + cuarzo + anfíbol + biotita. Las mesas de lava más recientes son El Rosario (0.30-0.23 Ma), El Carpintero (0.14 Ma) y El Bosque (0.15-0.10 Ma) (Dobson y Mahood, 1985; Macías et al., 2008; Arce et al., 2012). Se obtuvieron seis muestras de esta subunidad para análisis químicos de algunas mesas de lava y de los volcanes Guangoche y El Mozo (Tabla 1).

\section{TÉCNICAS ANALÍTICAS}

\section{Análisis petrográfico}

Se realizaron descripciones petrográficas de 13 muestras de las diferentes unidades que conforman al CVLA. En las secciones delgadas se identificaron fenocristales $(300 \mu \mathrm{m})$, microfenocristales $(300-3 \mu \mathrm{m})$, matriz $(<3 \mu \mathrm{m}$; microlítica o vítrea) y vesículas. Para la descripción petrográfica se utilizó un microscopio petrográfico marca Leica con cámara digital integrada. De manera general se describieron las principales fases minerales, su forma, textura y su abundancia relativa. Adicionalmente, se realizaron análisis modales de algunas de las secciones delgadas (Tabla 2); se contabilizaron entre 440 y 1850 puntos, teniendo en cuenta una distancia entre puntos de $0.5 \times 1 \mathrm{~mm}$ y de $1 \times 1 \mathrm{~mm}$, usando un contador de puntos marca Pelcon. La cantidad de puntos contados, así como la distancia entre ellos, dependió del área con la que se contaba en cada sección delgada y del tamaño de grano predominante en éstas.

\section{Análisis químico por FRX e ICP-MS}

La concentración de elementos mayores, traza y tierras raras de las diferentes unidades del CVLA fueron obtenidas con las técnicas analíticas de fluorescencia de rayos-X (FRX) y de espectrometría de masas con plasma inductivamente acoplado (ICP-MS). En total se realizaron 22 análisis químicos de roca total (Tabla 1 ).

Para estos análisis, las muestras fueron trituradas y pulverizadas con un molino vibratorio Herzog-HSM100 con discos de acero. El polvo obtenido de cada muestra fue homogenizado y cuarteado con el objetivo de obtener alícuotas representativas de la muestra original, en donde $\sim 20$ gr y $\sim 5$ gr de polvo fueron destinados para los análisis químicos de roca total por FRX e ICP-MS, respectivamente.

Para el análisis de elementos mayores por FRX se utilizaron tabletas de muestra fundida que fueron elaboradas calentado a $1100{ }^{\circ} \mathrm{C}$ y enfriando una mezcla que incluye $1 \mathrm{gr}$ de muestra en polvo, $4.5 \mathrm{gr}$ de $\mathrm{LiBO}_{2}$ y 4.5 gr de $\mathrm{Li}_{2} \mathrm{~B}_{4} \mathrm{O}_{7}$ (Lozano-Santa Cruz et al., 1995). La medición de las concentraciones se realizó siguiendo la metodología descrita por Lozano-Santa Cruz y Bernal (2005), utilizando un espectrómetro secuencial de rayos-X Rigaku ZSX Primus II previamente calibrado 
Tabla 1. Composición química de roca total de las muestras del Campo Volcánico de Los Azufres (CVLA) y de las rocas intrusivas que se utilizaron para los modelos petrogenéticos, obtenida por medio de FRX e ICP-MS.

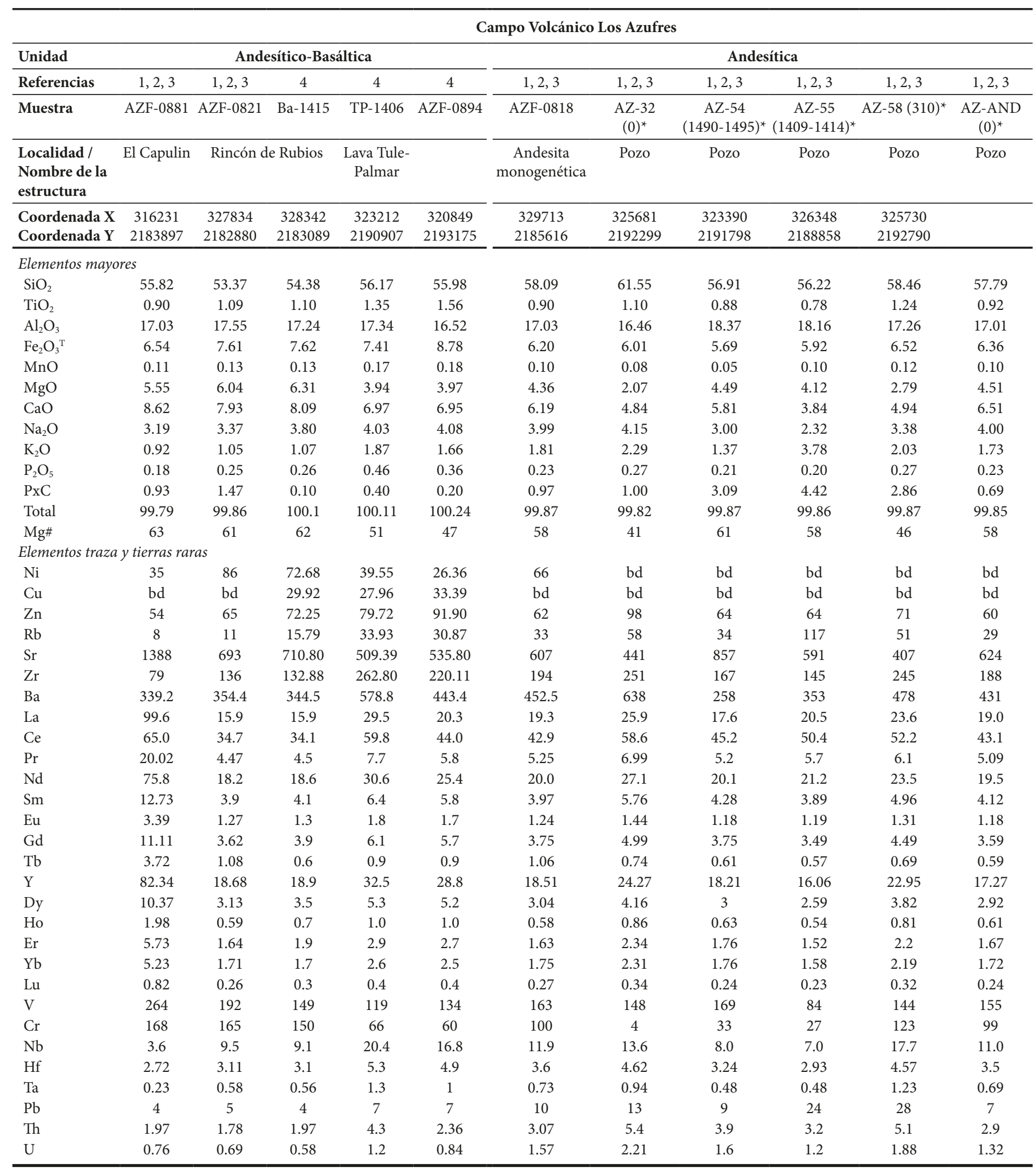


Tabla 1 (continuación). Composición química de roca total de las muestras del Campo Volcánico de Los Azufres (CVLA) y de las rocas intrusivas que se utilizaron para los modelos petrogenéticos, obtenida por medio de FRX e ICP-MS.

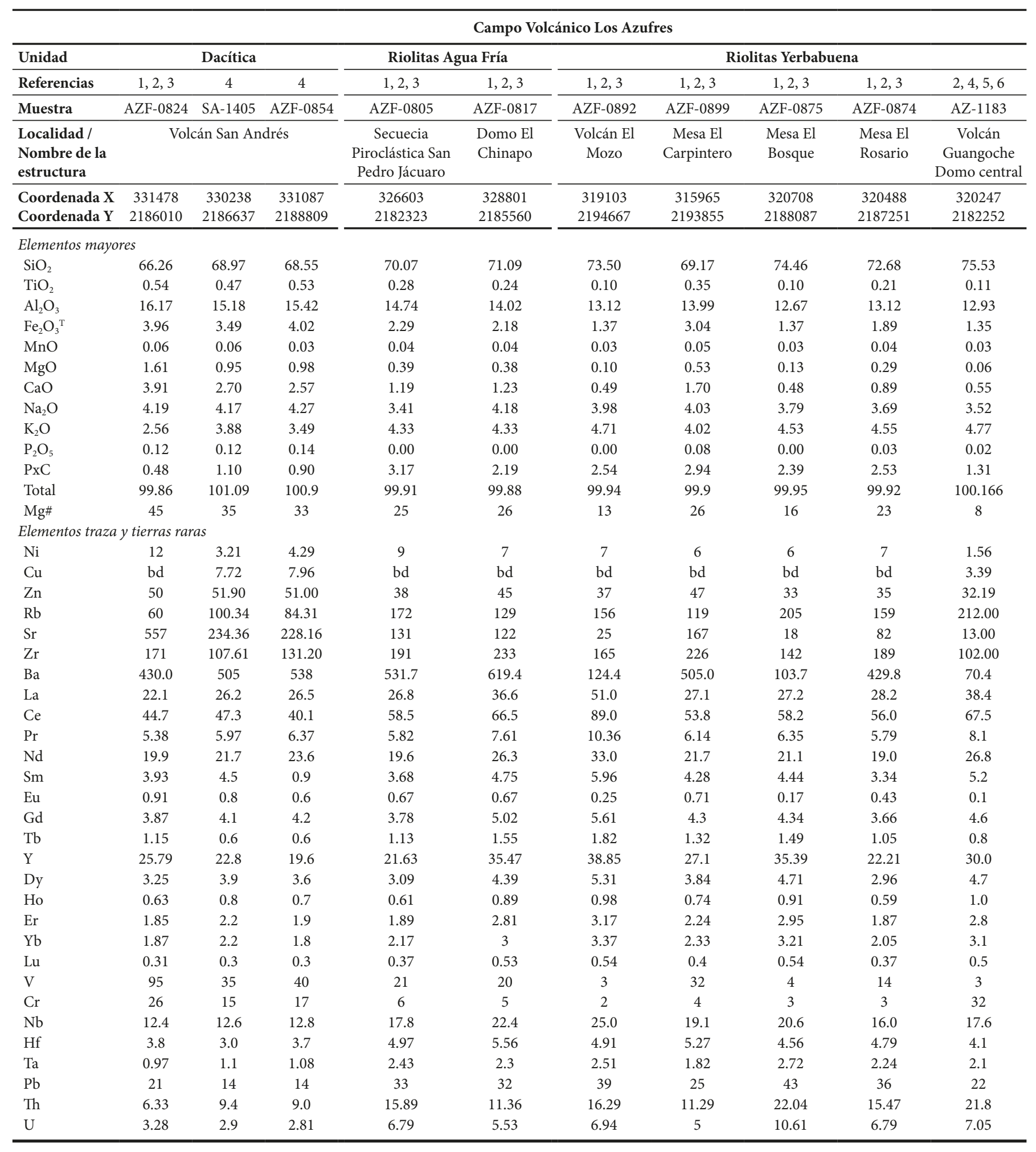


Tabla 1 (continuación). Composición química de roca total de las muestras del Campo Volcánico de Los Azufres (CVLA) y de las rocas intrusivas que se utilizaron para los modelos petrogenéticos, obtenida por medio de FRX e ICP-MS.

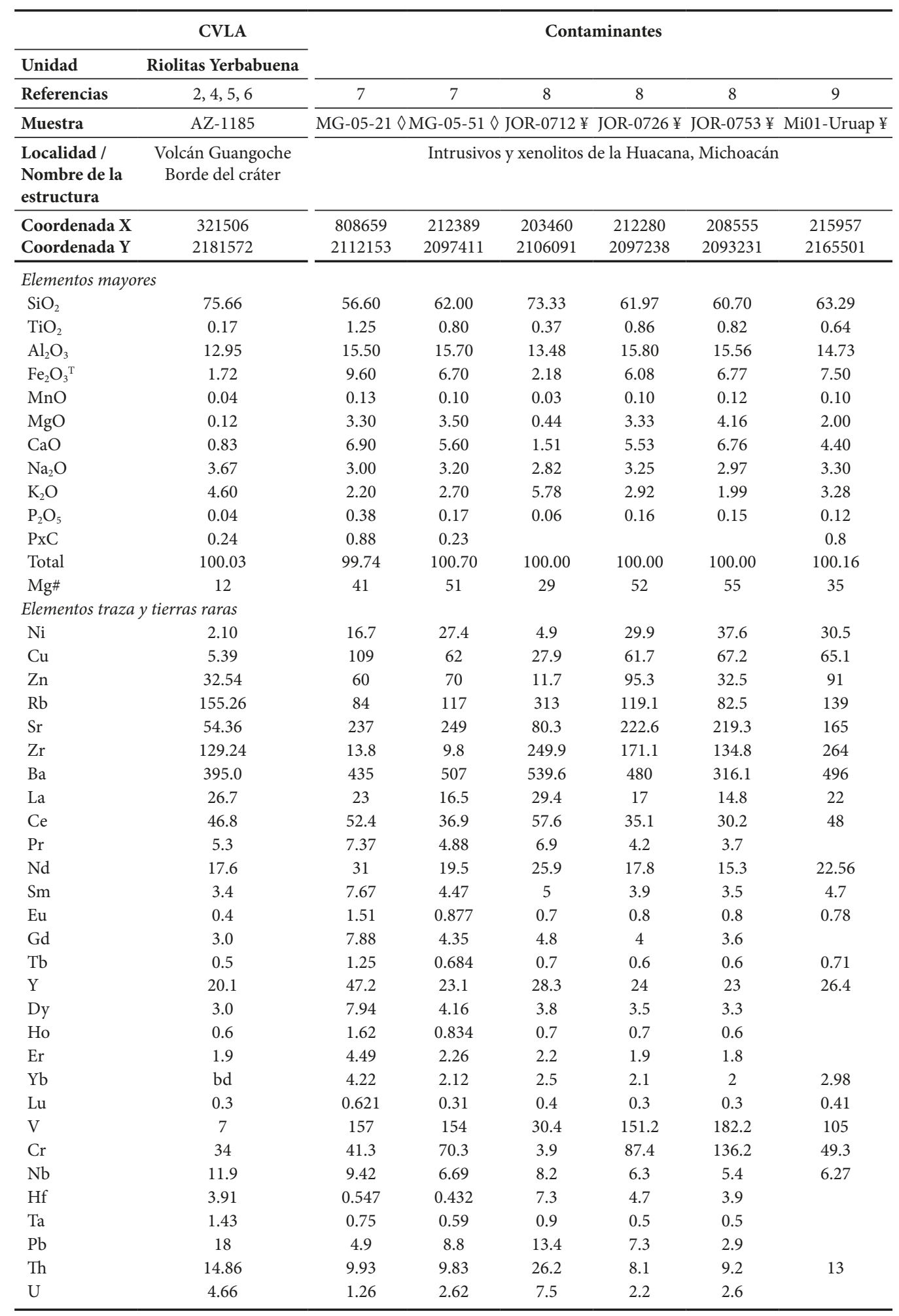

Los datos de los elementos mayores están reportados como valores no normalizados, a excepción de las muestras JOR-0712, JOR-072 y JOR-0753 que están en base anhidra. ${ }^{*}$ Profundidad en metros de las muestras de los pozos; $\mathrm{Fe}_{2} \mathrm{O}_{3}{ }^{\mathrm{T}}$ como Fe total; $\mathrm{PxC}$ = pérdida por calcinación; bd = debajo del límite de detección; $\mathrm{Mg} \#=\left(\mathrm{Mg} /\left(\mathrm{Mg}+\mathrm{Fe}_{\mathrm{total}^{2+}}\right)\right)^{*}$ 100. - Referencias: Elementos mayores: 1 = Macías et al. (2008); 2 = Arce et al. (2012). Elementos traza y tierras raras: $3=$ Este trabajo. Elementos mayores, traza y tierras raras: $4=$ Rangel (2019); $5=$ Rangel (2013); $6=$ Rangel et al. (2018). Muestras de los intrusivos ( () y xenolitos (¥) de la Huacana, Michoacán: 7 = Ortega-Gutiérrez et al. (2014); 8 = Rasoazanamparany et al. (2016); 9 = Corona-Chávez et al. (2006). -Las coordenadas UTM de la muestra MG05-21 pertenecen a las zona $13 \mathrm{Q}$, las demás coordenadas son de la zona $14 \mathrm{Q}$. 
Tabla 2. Porcentajes modales correspondienes a algunas muestras de las unidades del Campo Volcánico de Los Azufres.

\begin{tabular}{|c|c|c|c|c|c|c|c|c|c|c|}
\hline & \multirow{2}{*}{\multicolumn{4}{|c|}{ Unidad Basáltica }} & \multicolumn{6}{|c|}{ Unidad Riolítica } \\
\hline & & & & & \multicolumn{4}{|c|}{ Riolitas Agua Fría } & \multicolumn{2}{|c|}{ Riolitas Yerbabuena } \\
\hline & Ba-1415 & $\pm 2 \sigma$ & TP-1406 & $\pm 2 \sigma$ & Ros-1413 & $\pm 2 \sigma$ & AZ-1185 & $\pm 2 \sigma$ & AZ-1183 & $\pm 2 \sigma$ \\
\hline Matriz & 92.0 & 1.2 & 85.5 & 5 & 58.8 & 2.8 & 73.1 & 3.5 & 54.6 & 3.5 \\
\hline Vesículas & 3.3 & 0.8 & & & 20.7 & 2.5 & 1.1 & 1 & 25.3 & 0.6 \\
\hline Olivino & 2.8 & 0.7 & & & & & & & & \\
\hline Clinopiroxeno & 0.3 & 0.1 & & & & & & & & \\
\hline Ortopiroxeno & 0.4 & 0.1 & & & & & & & & \\
\hline Plagioclasa & 1.2 & 0.3 & 14.5 & 3.5 & 4.9 & 1.1 & 6.7 & 1.5 & 5.3 & 1.8 \\
\hline Anfíbol & & & & & 1.6 & 0.3 & 0.2 & 0.5 & 0.06 & 0.1 \\
\hline Biotita & & & & & 2.1 & 0.5 & 0.3 & 1 & 0.9 & 1.2 \\
\hline Óxidos Fe-Ti & & & & & 0.3 & 0.1 & & 1.5 & 0.2 & 0.1 \\
\hline Sanidino & & & & & 5.8 & 1.2 & 7.3 & 1.5 & 5.6 & 1.8 \\
\hline Cuarzo & & & & & 5.8 & 1.2 & 7.9 & 1.5 & 8.1 & 2 \\
\hline
\end{tabular}

La desviación estándar $( \pm 2 \sigma)$ de los análisis modales se calculó con ayuda de la tabla de Van der Plas y Tobi (1965).

con muestras internacionales de referencia geoquímica. Ambos procedimientos se realizaron en el Laboratorio Nacional de Geoquímica y Mineralogía, UNAM, en el Instituto de Geología.

La preparación y medición de las muestras para determinar la concentración de los elementos traza y tierras raras por ICP-MS, se realizó en el Laboratorio de Estudios Isotópicos del Centro de Geociencias, UNAM en Juriquilla, Querétaro, siguiendo la metodología descrita en Mori et al. (2007). En donde las muestras previamente digeridas en una serie de ácidos ( $\mathrm{HF}, 8 \mathrm{~N} \mathrm{HNO}_{3}, 16 \mathrm{~N} \mathrm{HNO}_{3}, 8 \mathrm{~N} \mathrm{HNO}_{3}$ ), fueron diluidas en una solución estándar de preparación interna que contiene $0.2 \mathrm{~N}$ $\mathrm{HNO}_{3}, 10$ partes por billón (ppb) de Ge, 5 ppb de In, 5 partes por millón (ppm) de Tm, y 5 ppb de Bi, con el fin de proveer las concentraciones adecuadas dentro de los límites de detección del instrumento, y para obtener la señal necesaria para adquirir datos de alta precisión (Mori et al., 2007). Las concentraciones de elementos traza y tierras raras se midieron con un espectrómetro de masas cuadrupolar con plasma acoplado por inducción, modelo Thermo Series XII.

\section{RESULTADOS}

\section{Petrografía}

\section{Unidad Andesítico-Basáltica}

De esta unidad se analizaron dos muestras de lava. Una de ellas aflora al sur del domo riolítico "El Chinapo" (muestra Ba-1415; Figura 3) y otra se ubica al norte de la mesa de lava "El Bosque" (muestra TP-1406; Figura 3). En general, las rocas son inequigranulares, presentan texturas porfídicas y tienen una paragénesis mineral de fenocristales (310-849 $\mu \mathrm{m})$ y microfenocristales $(37-295 \mu \mathrm{m})$ de olivino $(2.8 \%)$, plagioclasa ( $1.2 \%)$, ortopiroxeno $(0.4 \%)$ y clinopiroxeno ( $0.3 \%$; Tabla 2$)$, inmersos en una mesostasis hipocristalina con textura intersticial y un arreglo subtraquítico; los intersticios están ocupados por vidrio y cristales de piroxeno, óxidos y olivino. Los fenocristales y microfenocristales comúnmente forman glomerocristales (Figura 4a-4d, F). El olivino tiene formas subédricas y anédricas, presenta alteración iddingsítica

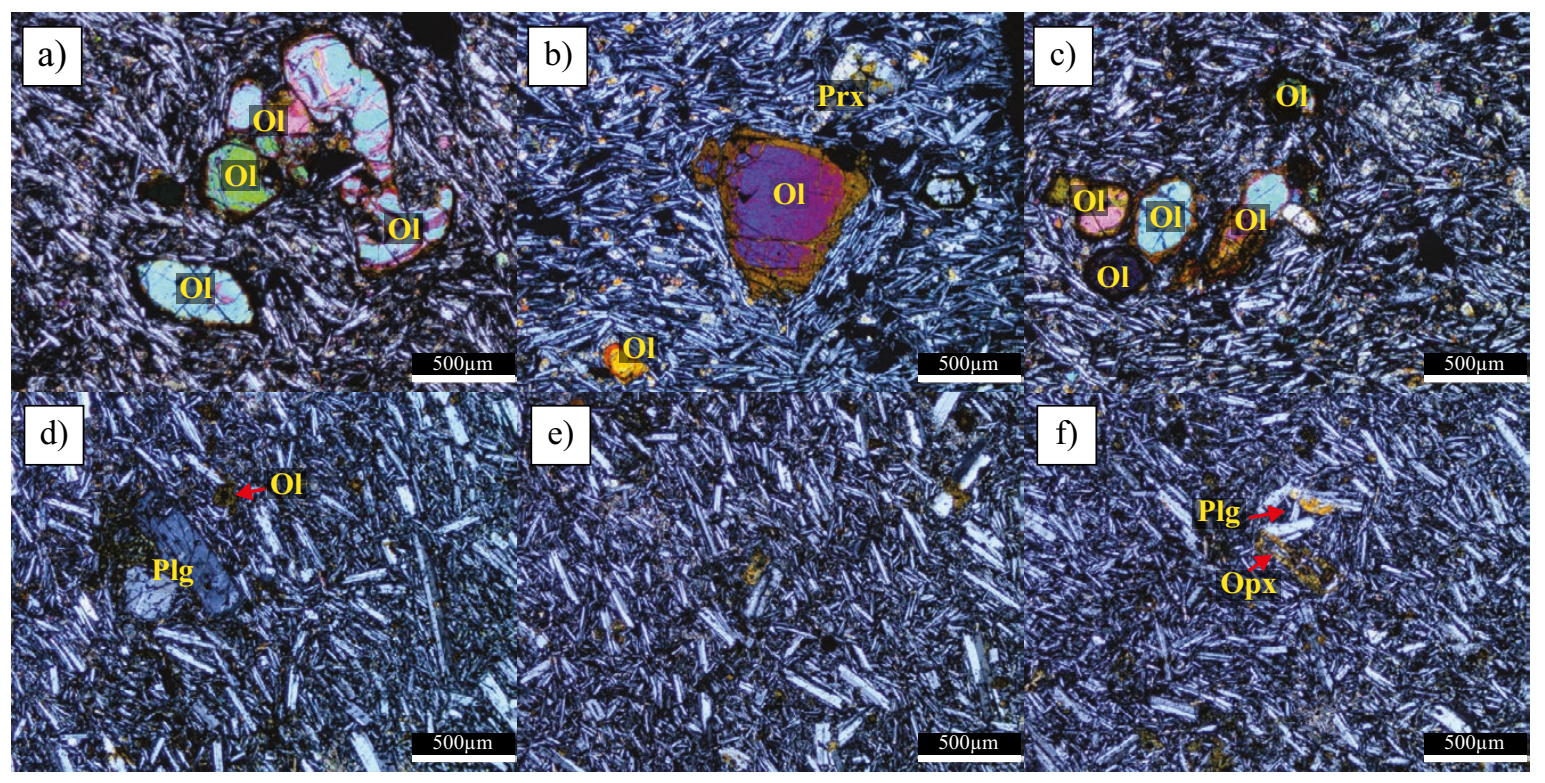

Figura 4. Microfotografías en luz polarizada de las muestras Ba-1415 (a-c) y TP-1406 (d-f) pertenecientes a la Unidad Andesítico-Basáltica del Campo Volcánico de Los Azufres. $\mathrm{Ol}=$ olivino; $\mathrm{Prx}=$ piroxeno; Plg = plagioclasa; $\mathrm{Opx}=$ ortopiroxeno. Para la ubicación de las muestras ver mapa de la Figura 3. 


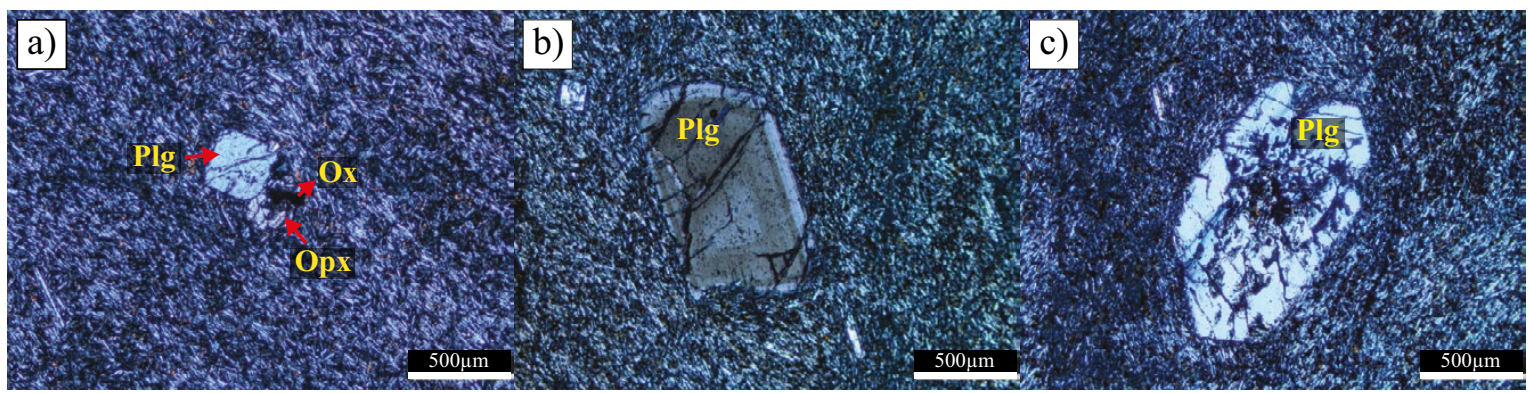

Figura 5. Microfotografías en luz polarizada de la muestra An-1407 perteneciente a la Unidad Andesítica del Campo Volcánico de Los Azufres. Plg = plagioclasa; $\mathrm{Opx}=$ ortopiroxeno; $\mathrm{Ox}=$ óxidos. Para la ubicación de la muestra ver mapa de la Figura 3.

a lo largo de los bordes y fracturas, y además contiene inclusiones de óxidos (Figura 4a-4c). La plagioclasa generalmente presenta formas euédricas, aunque hay algunos cristales que muestran reabsorción a lo largo de los bordes (Figura 4d). Los orto y clinopiroxenos son de menor dimensión y presentan formas subédricas (Figura 4b y 4f).

\section{Unidad Andesítica}

Las rocas de esta unidad son hipocristalinas, con textura microlítica con escasos $(\sim 1 \%)$ fenocristales $(310-1380 \mu \mathrm{m})$ y microfenocristales $(90-260 \mu \mathrm{m})$ de plagioclasa y ortopiroxeno (Figura 5). La matriz representa aproximadamente el $99 \%$ en volumen de toda la roca y está constituida por vidrio, así como por microlitos de plagioclasa (los cuales a su vez presentan textura traquítica), óxidos y piroxeno (Figura 5). La plagioclasa tiene formas euédricas y subédricas, algunos cristales muestran zoneamiento (Figura $5 \mathrm{a}$ y $5 \mathrm{~b}$ ), mientras que otros (generalmente los de mayor tamaño) exponen rasgos de desequilibrio como bordes y centros reabsorbidos (Figura 5c). También se encuentran algunos glomerocristales de este mineral. El ortopiroxeno muestra formas subédricas y euédricas, algunos cristales presentan inclusiones de óxidos y se encuentran de forma independiente en la matriz o compartiendo bordes con cristales de plagioclasa (Figura 5a).

\section{Unidad Dacítica}

La Unidad Dacítica (representada por el volcán San Andrés) es hipocristalina, porfídica, constituida por fenocristales y microfenocristales de plagioclasa, piroxeno, anfíbol, biotita, óxidos de Fe-Ti y ocasionalmente cuarzo y circón (Figura 6). Todos estos minerales se encuentran inmersos en una matriz conformada por vidrio perlitizado y microlitos de plagioclasa tabular, euédrica y con textura pilotaxítica (Figura 6a).

La plagioclasa está representada por dos poblaciones, la primera son microfenocristales $(120-266 \mu \mathrm{m})$ y fenocristales $(<\sim 1 \mathrm{~mm})$ con formas euédricas y zoneamiento (Figura $6 \mathrm{~b}$ ), mientras que la segunda se compone de grandes fenocristales (con tamaños de hasta $\sim 4 \mathrm{~mm}$ ) con formas subédricas y rasgos de desequilibrio (disolución y textura de tamiz; Figura 6c). El ortopiroxeno se encuentra como microfenocristal $(84-291 \mu \mathrm{m})$ (Figura 6a) y el clinopiroxeno está como fenocristal (300-1680 $\mu \mathrm{m})$ (Figura 6b y 6d); ambos presentan formas euédricas y subédricas, y en ocasiones se agrupan entre ellos o con algunos cristales de plagioclasa para formar glomerocristales. Pocos clinopiroxenos se observan con bordes y centros disueltos (Figura 6d). La biotita y el anfíbol están presentes como fenocristales (309-1479 $\mu \mathrm{m})$ y escasamente como microfenocristales (66-297 $\mu \mathrm{m})$; ambos con

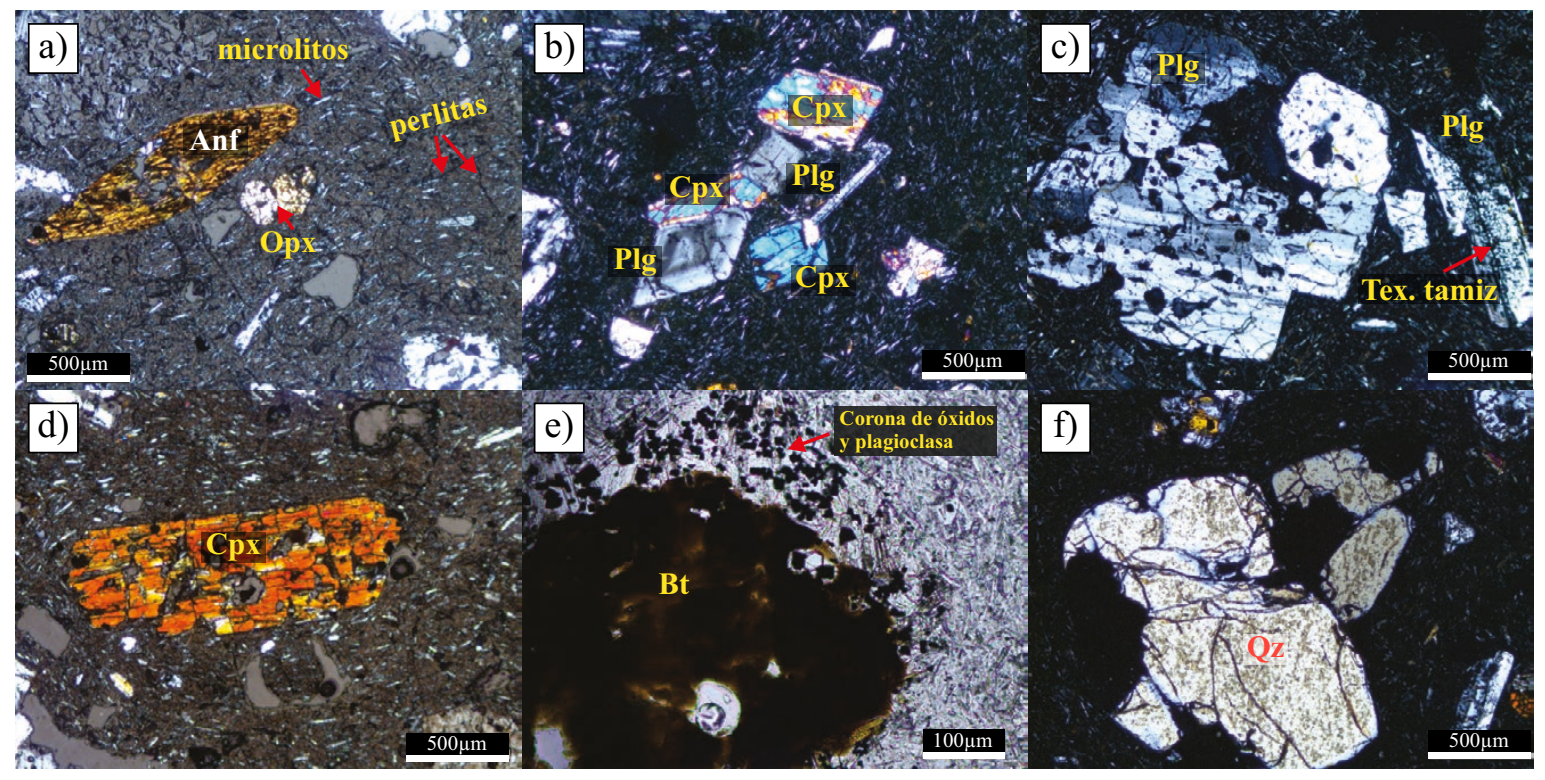

Figura 6. Microfotografías de las lavas de la Unidad Dacítica (muestra SA-1405) del Campo Volcánico de Los Azufres. Anf = anfíbol; Opx = ortopiroxeno; Cpx = clinopiroxeno; $\mathrm{Plg}=$ plagioclasa; $\mathrm{Bt}=$ biotita; $\mathrm{Qz}=$ cuarzo. La microfotografía (e) está tomada en luz paralela, mientras que las demás se tomaron con luz polarizada. Para la ubicación de la muestra ver mapa de la Figura 3. 


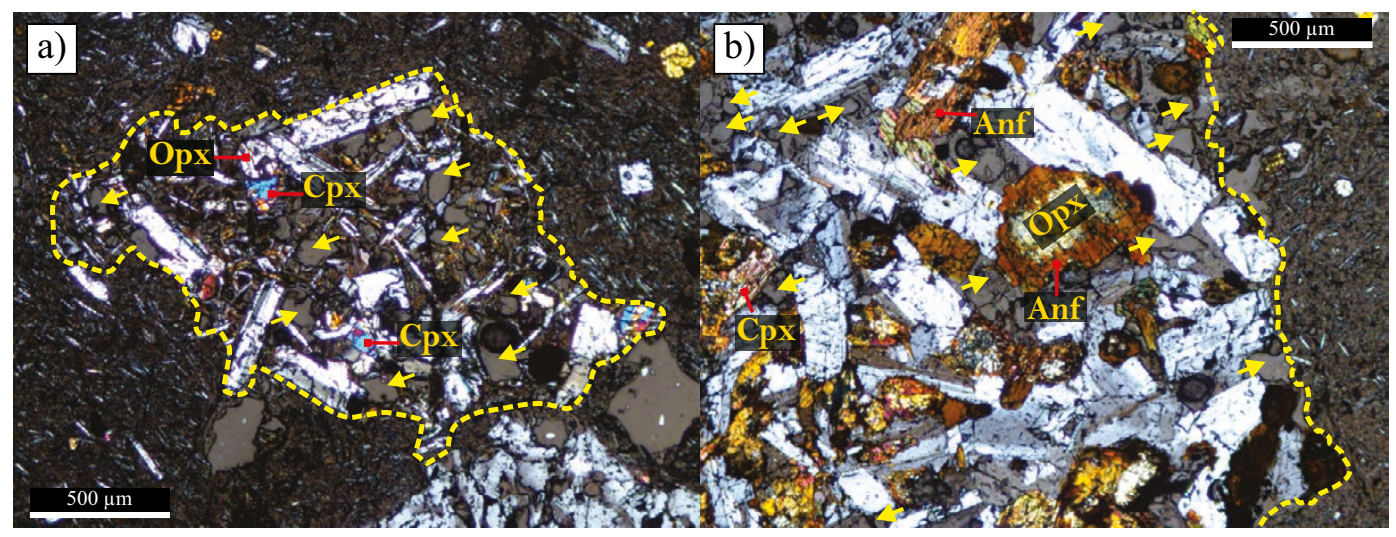

Figura 7. Microfotografías en luz polarizada de los enclaves magmáticos encontrados dentro de las lavas dacíticas del volcán San Andrés con textura porfídica (a) y equigranulares (b). Nótese la presencia de vesículas (señaladas con flechas) y vidrio intersticial. Opx = ortopiroxeno; Cpx = clinopiroxeno; Anf = anfíbol.

formas subédricas y euédricas. Algunos cristales de biotita contienen inclusiones de óxidos, mientras que otros se observan parcialmente oxidados o con coronas de óxidos y plagioclasa (Figura 6e). Los cristales de cuarzo son escasos en las muestras del volcán San Andrés; se encuentran como fenocristales $(\sim 2 \mathrm{~mm})$ con formas anédricas y golfos de corrosión (Figura 6f).

Las lavas del volcán San Andrés contienen abundantes enclaves magmáticos, los cuales oscilan en tamaños de entre $3.7 \mathrm{~cm}$ a $0.8 \mathrm{~mm}$ de longitud. En general, tienen formas ovaladas y presentan contactos irregulares (Figura 7), con textura porfídica y también equigranular (Figura 7 y 7 b). Los enclaves porfídicos constan de fenocristales (555-310 $\mu \mathrm{m})$ y microfenocristales $(<270 \mu \mathrm{m})$ euédricos y subédricos de plagioclasa, clinopiroxeno y ortopiroxeno (Figura 7a). Los enclaves equigranulares son de grano fino $(<1 \mathrm{~mm})$, con textura hipidiomórfica, constituidos por fenocristales subédricos de plagioclasa con zoneamiento, anfíbol, ortopiroxeno, óxidos de Fe-Ti y clinopiroxeno. En los bordes de los cristales de ortopiroxeno al parecer hay sobrecrecimiento de cristales de anfíbol (Figura 7b). Los óxidos de Fe-Ti se encuentran de forma aislada en la matriz y como inclusiones en anfíbol. Cabe mencionar, que ambos enclaves presentan vidrio intersticial y vesículas con formas redondeadas y ovaladas (Figura 7).

\section{Unidad Riolítica}

\section{Riolitas Agua Fría}

La lava de la mesa El Rosario es representativa de esta subunidad (muestra Ros-1413; Figura 3) así como las lavas del borde del cráter con forma de herradura del volcán Guangoche (muestra AZ-1185; Figura 3). En general, las rocas tienen texturas vitrofíricas y están constituidas por fenocristales y microfenocristales de cuarzo (7.9-5.8 \%), sanidino (7.3-5.8\%), plagioclasa (6.7-4.9\%), biotita (3.5-2.1\%), anfíbol (1.6-0.2\%), óxidos de Fe-Ti (0.3\%) y circón (Figura 8; Tabla 2). Dichos cristales se encuentran inmersos en una matriz vítrea y vesicular. En ocasiones se aprecian rasgos de desvitrificación, que origina texturas esferulíticas y perlíticas.

El cuarzo está presente como fenocristal (con tamaños de hasta

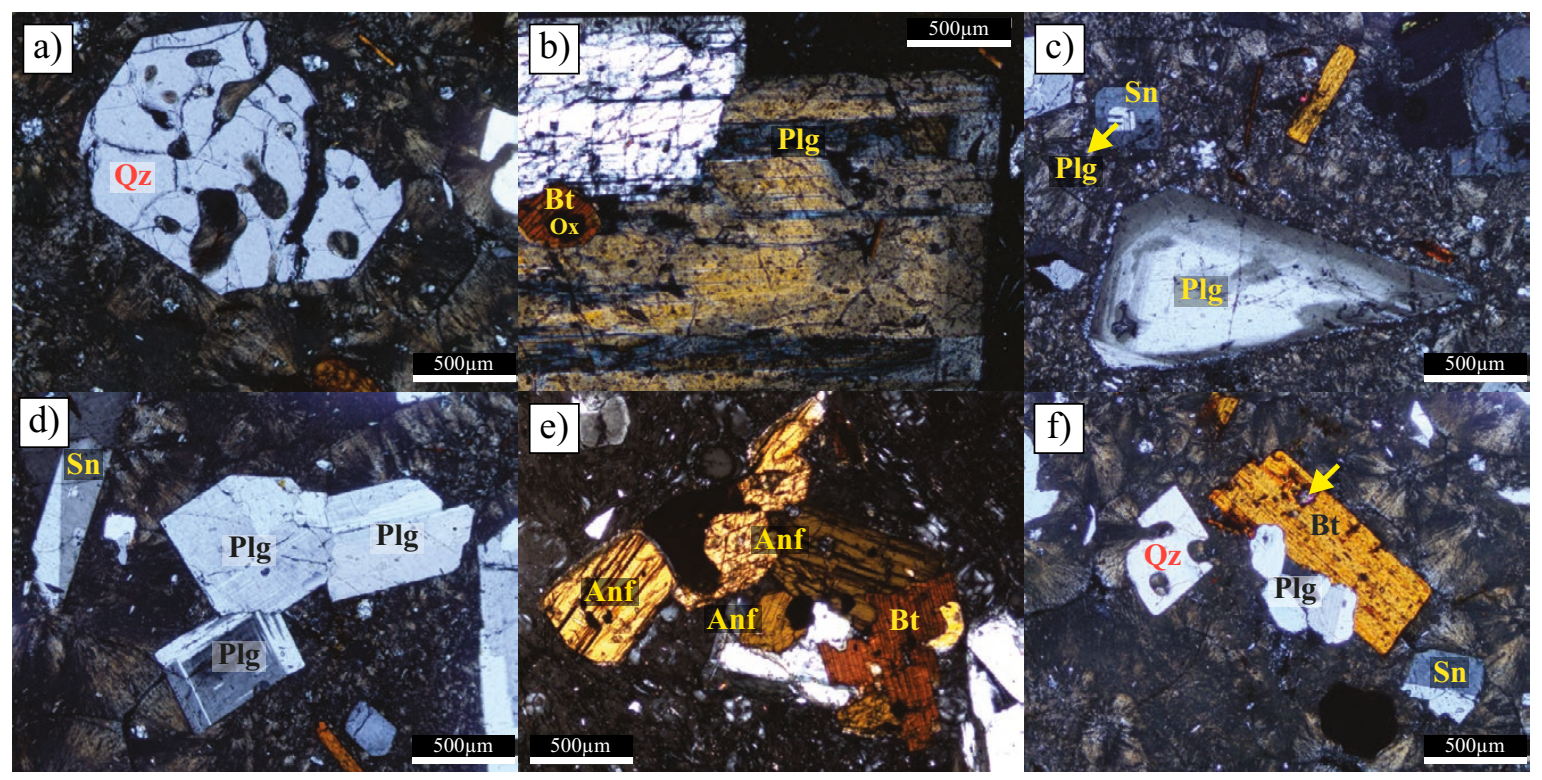

Figura 8. Microfotografías en luz polarizada de las muestras de la subunidad Riolitas Agua Fría. $\mathrm{Qz}=$ cuarzo; Plg = plagioclasa; $\mathrm{Bt}=$ biotita; Ox = óxidos de Fe-Ti; $\mathrm{Sn}$ = sanidino; Anf = anfíbol. La flecha en la microfotografía (f) señala a un cristal de circón como inclusión en un cristal de biotita. 


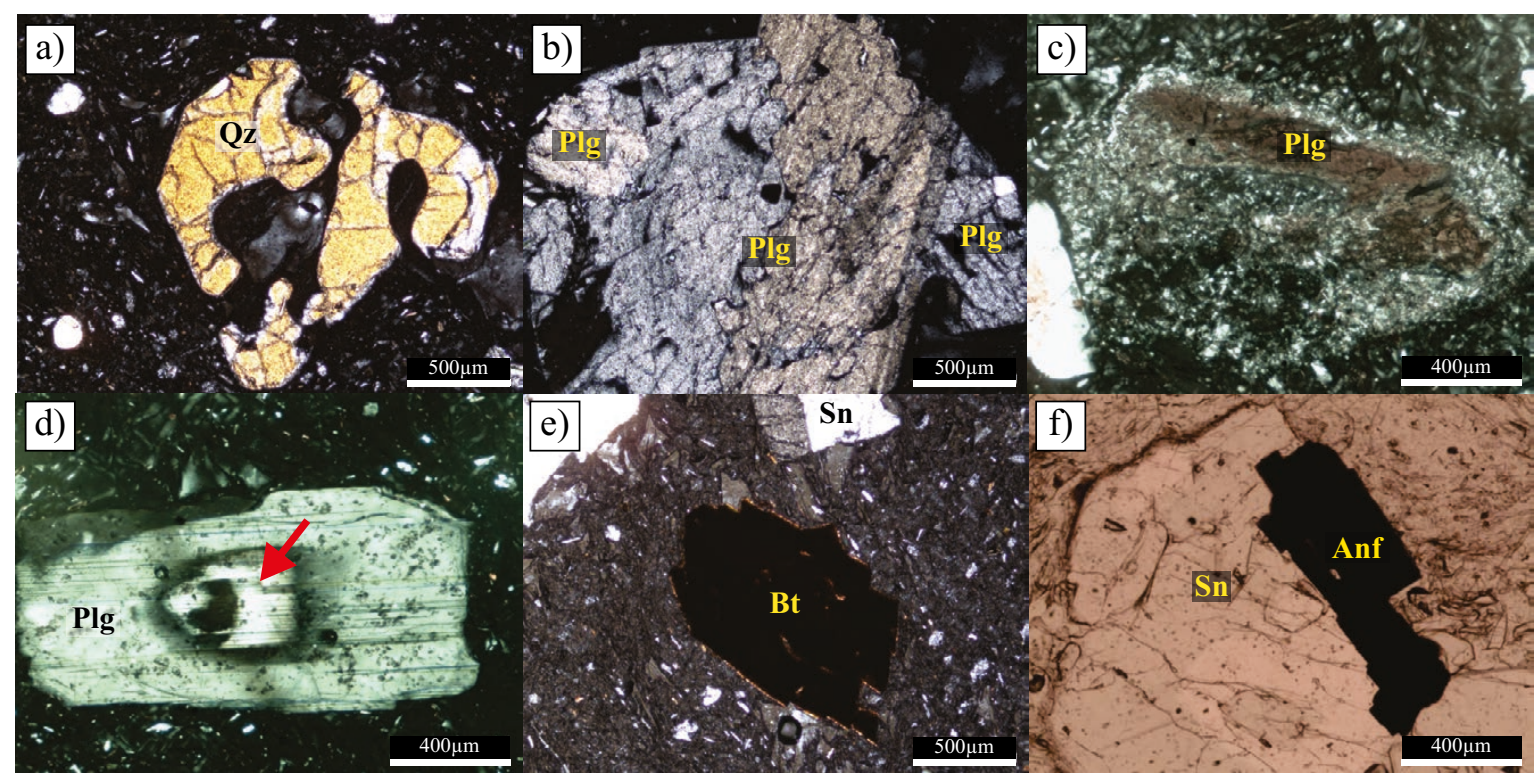

Figura 9. Microfotografías en luz polarizada (a-e) y luz paralela (f) de las muestras de la subunidad Riolitas Yerbabuena. Qz = cuarzo; $\mathrm{Plg}=$ plagioclasa; Bt = biotita; $\mathrm{Sn}=$ sanidino; Anf = anfíbol. c) Fenocristal de plagioclasa disuelto casi por completo. La flecha en la microfotografía (d) señala a un núcleo de plagioclasa con bordes anédricos, embebido en un fenocristal subédrico de plagioclasa.

$1.5 \mathrm{~mm}$ de longitud) con formas subédricas y anédricas; tiene golfos de corrosión (Figura 8a) e inclusiones de vidrio, biotita, anfíbol y óxidos de Fe-Ti. Los minerales feldespáticos (sanidino y plagioclasa) exhiben formas subédricas y euédricas, forman glomerocristales y oscilan en tamaños que van de $170 \mu \mathrm{m}$ a $\sim 2 \mathrm{~mm}$. La mayoría de los cristales de plagioclasa presentan zoneamiento y contienen inclusiones de anfíbol, biotita y circón (Figura 8 b y 8c). El sanidino muestra bordes de reabsorción, así mismo contiene inclusiones de plagioclasa. La biotita y el anfíbol tienen formas subédricas y euédricas, con dimensiones de $230 \mu \mathrm{m}$ a $1.2 \mathrm{~mm}$. En particular, la biotita contiene inclusiones de óxidos de Fe-Ti y de circón, y comparte bordes con cristales de plagioclasa y cuarzo (Figura 8 b y $8 \mathrm{f}$ ). Como mineral accesorio se observaron algunos microfenocristales $(<150 \mu \mathrm{m})$ de circón con formas euédricas (Figura 8f) y con inclusiones de apatito y óxidos.

\section{Riolitas Yerbabuena}

Como estructuras volcánicas representativas de esta subunidad está el domo del volcán Guangoche (muestra AZ-1183; Figura 3) y la lava de la mesa El Bosque (muestra Bos-1412; Figura 3). A grandes rasgos, las rocas muestran texturas vitrofíricas, con una paragénesis mineral de fenocristales y microfenocristales de cuarzo (8.1\%), sanidino (5.6\%), plagioclasa (5.3\%), biotita (0.9\%), óxidos de Fe-Ti (0.2\%), anfíbol $(0.06 \%)$ y circón, inmersos en una matriz vítrea y vesicular (Figura 9; Tabla 2).

El cuarzo se presenta como fenocristal con formas anédricas y en ocasiones subédricas, tiene golfos de corrosión (Figura 9a) y algunos cristales se observan con bordes de disolución. La plagioclasa y el sanidino son fenocristales subédricos. La mayoría de los cristales de plagioclasa presentan zoneamiento y forman glomerocristales con otros minerales (Figura 9b). Algunos están parcialmente disueltos, mientras que otros ocurren como núcleos con bordes anédricos y subédricos en plagioclasa y sanidino (Figura 9c y 9d). Los cristales de biotita y anfíbol están como fenocristales y microfenocristales con formas subédricas y euédricas; en donde la mayoría de éstos están reemplazados casi en su totalidad por óxidos (Figura 9e y 9f). El circón se encuentra como microfenocristal euédrico y subédrico de forma independiente en la matriz y con inclusiones de óxidos de Fe-Ti.

\section{Geoquímica}

Las rocas del Campo Volcánico de Los Azufres fueron divididas en cuatro grupos, con base en su mineralogía y composición química en base anhidra (Tabla 1). Las muestras de la Unidad AndesíticoBasáltica en el diagrama de Le Bas et al. (1986) se ubican en el campo de la andesita basáltica (Figura 10), con contenidos de $\mathrm{SiO}_{2}$ de 54.2 a $56.5 \%$ en peso y álcalis entre 4.2 y $5.9 \%$ en peso. Las muestras de la

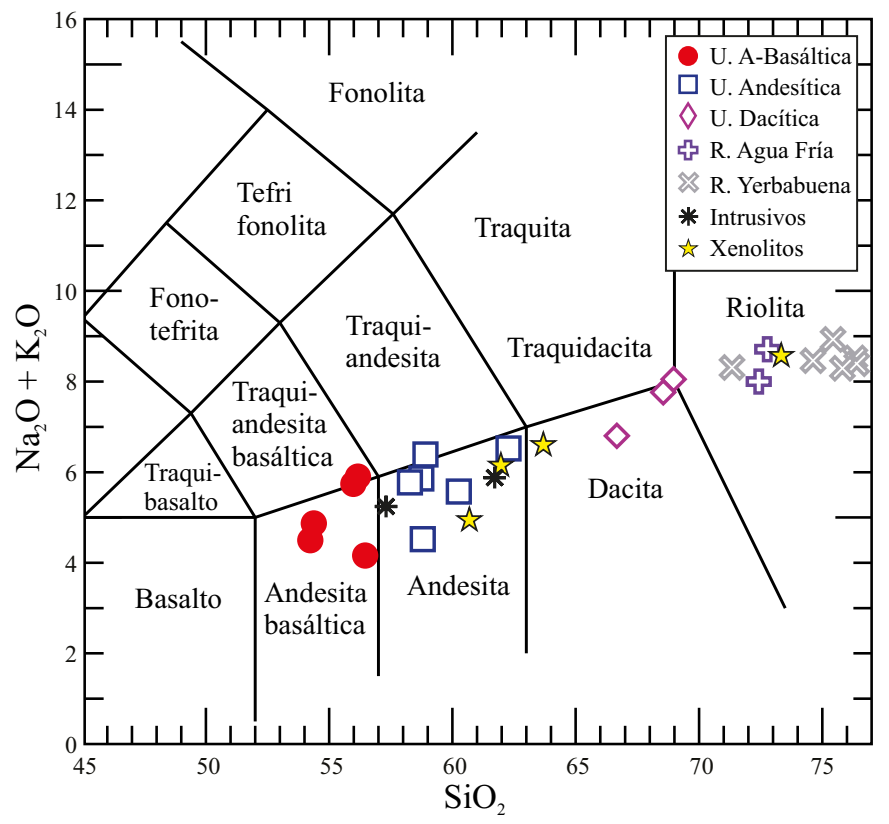

Figura 10. Diagrama de álcalis total $\left(\mathrm{Na}_{2} \mathrm{O}+\mathrm{K}_{2} \mathrm{O}\right)$ versus sílice (Le Bas et al., 1986) para la clasificación química de las rocas del Campo Volcánico de Los Azufres. También se grafican las rocas intrusivas de La Huacana, Michoacán (Ortega-Gutiérrez et al., 2014) y los xenolitos encontrados dentro de los productos de los volcanes Jorullo y Arócutin (Corona-Chávez et al., 2006; Rasoazanamparany et al., 2016). 

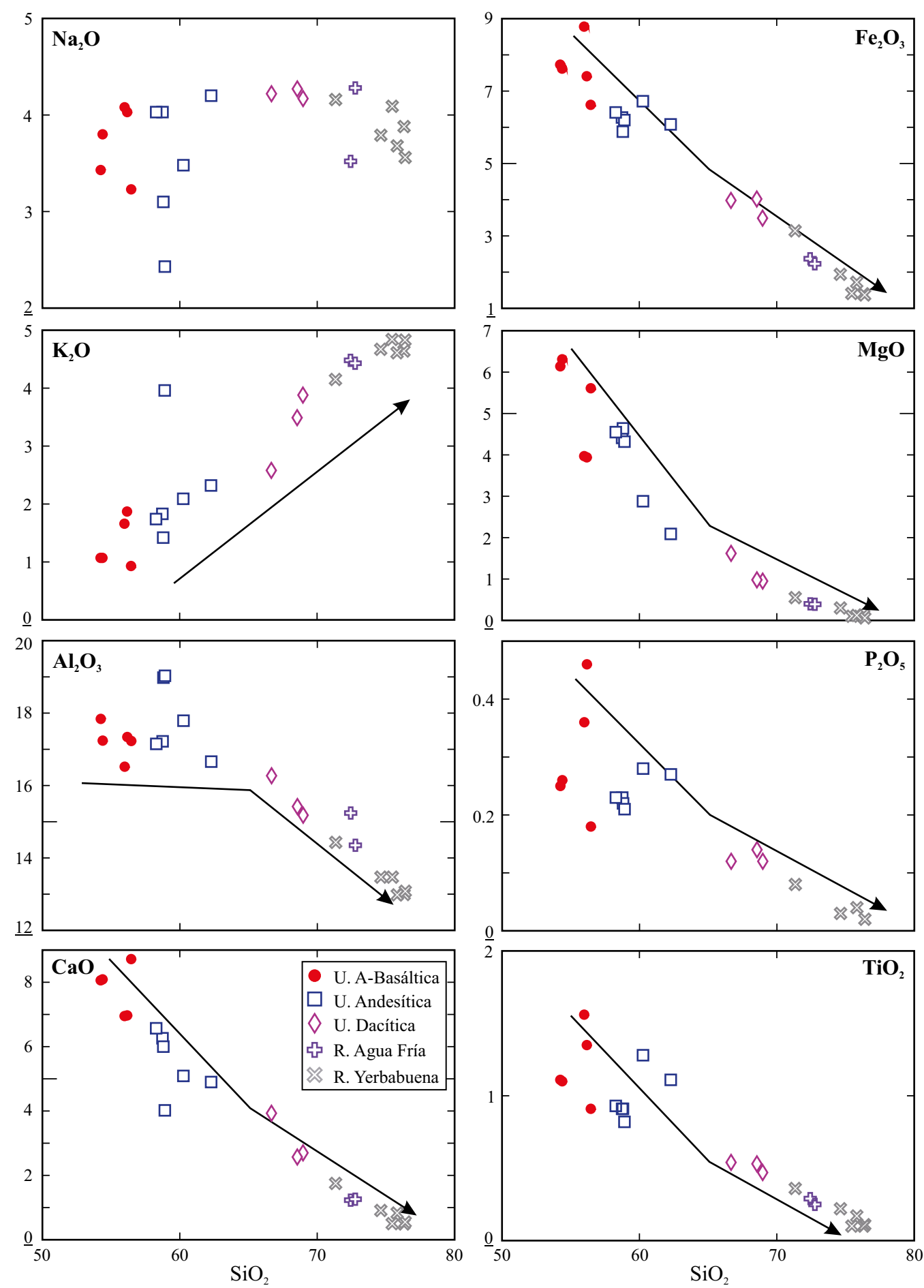

Figura 11. Diagramas binarios que grafican la variación en el contenido de los elementos mayoritarios con el contenido de $\mathrm{SiO}_{2}$ para las muestras del Campo Volcánico de Los Azufres. Las flechas indican posibles tendencias de evolución magmática.

Unidad Andesítica varían de 58.3 a $62.3 \%$ en peso de $\mathrm{SiO}_{2}$ y álcalis de 4.5 a $6.5 \%$ en peso. De la Unidad Dacítica solamente se analizaron tres muestras, con variaciones de $\mathrm{SiO}_{2}$ de 66.7 a $69 \%$ en peso de $\mathrm{SiO}_{2}$ y álcalis entre 6.8 y $8.1 \%$ en peso de álcalis.

Las muestras de la Unidad Riolítica tienen una variación más evidente, por lo que se pueden distinguir las dos subunidades, ya que la Riolita Agua Fría tiene entre 72 y $73 \%$ en peso de $\mathrm{SiO}_{2}$ y entre 8 y 8.7 $\%$ en peso de álcalis, mientras que la Riolita Yerbabuena es predomi- nantemente más silícica (con $~ 76.4 \%$ en peso de $\mathrm{SiO}_{2}$ y álcalis $\sim 8.9 \%$ en peso; Figura 10; Tabla 1). Adicionalmente, estas dos subunidades tienen claras diferencias en cuanto a elementos traza, como se reporta más adelante (ver Tabla 1).

En el diagrama de clasificación química (Le Bas et al., 1986; Figura 10), se aprecia que todas las muestras del CVLA despliegan una tendencia ascendente del contenido de álcalis con respecto $\mathrm{al} \mathrm{SiO}_{2}$. Mientras que en los diagramas binarios, es notoria la correlación positiva del 


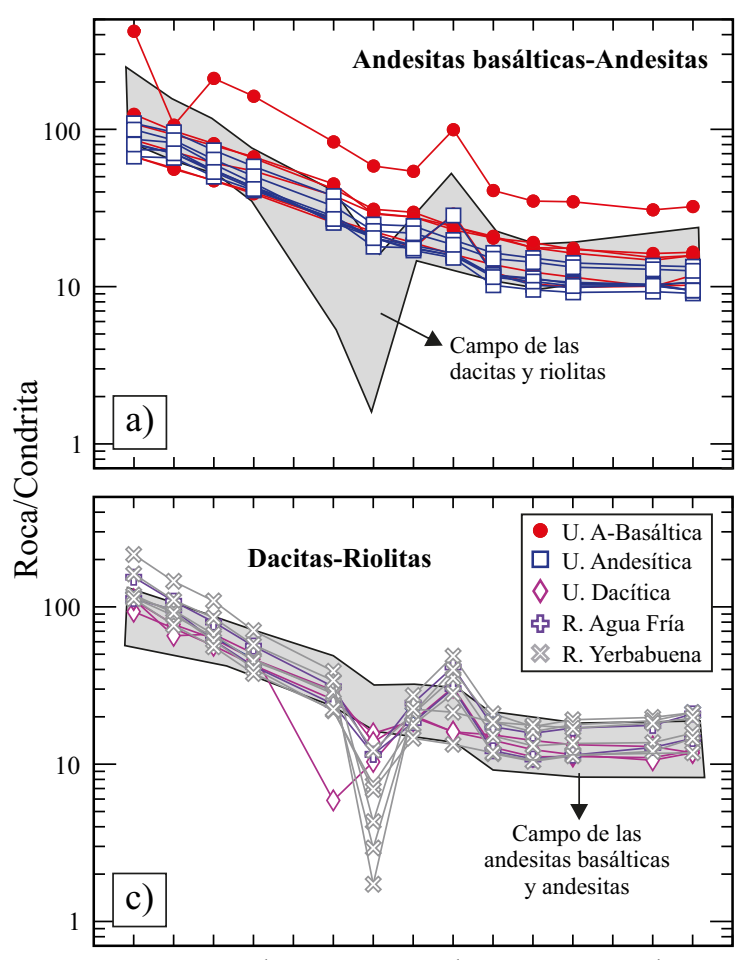

La $\mathrm{Ce}$ Pr Nd Pm Sm Eu Gd Tb Dy Ho Er Tm Yb Lu

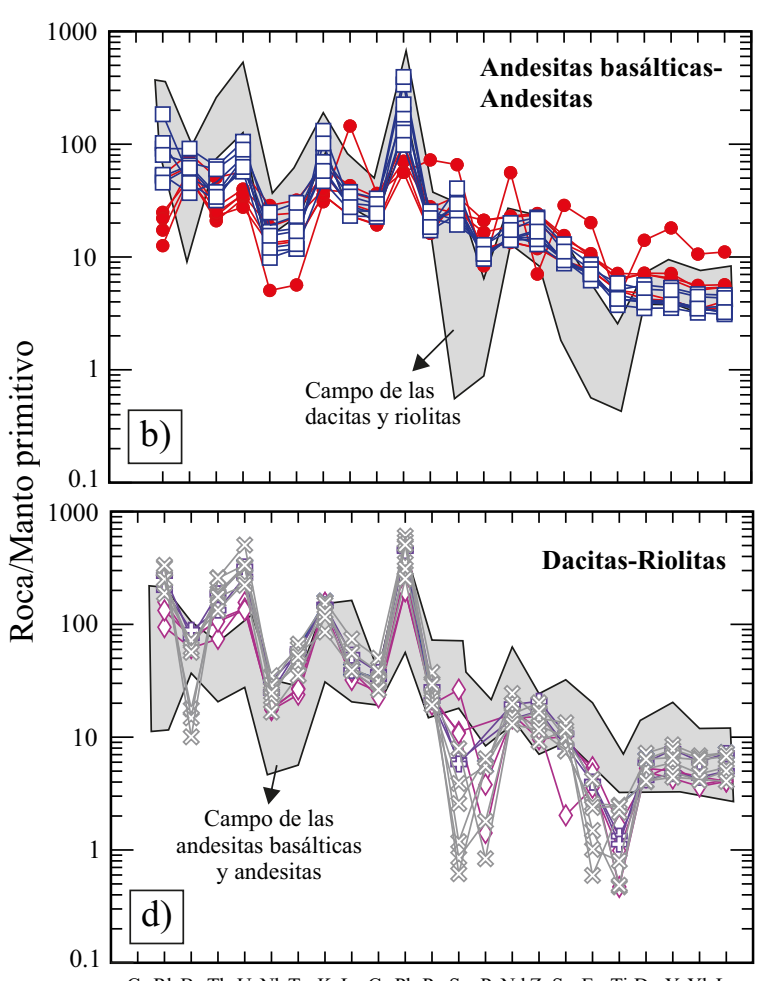

Cs RbBa Th U Nb Ta K La Ce Pb Pr Sr P NdZrSmEu Ti Dy Y YbLu

Figura 12. a, c) Diagrama de tierras raras normalizado con respecto a la composición de la condrita de Sun y McDonough (1989) para las muestras del Campo Volcánico de Los Azufres (CVLA). b, d) Diagrama multielemental normalizado con respecto a la composición del manto primitivo (Sun y McDonough, 1989) para las rocas del CVLA.

$\mathrm{K}_{2} \mathrm{O}$ con el aumento del $\mathrm{SiO}_{2}$, a diferencia del $\mathrm{Na}_{2} \mathrm{O}$, que despliega una tendencia horizontal burda (Figura 11). Para los demás elementos $\left(\mathrm{Fe}_{2} \mathrm{O}_{3}, \mathrm{CaO}, \mathrm{MgO}, \mathrm{TiO}_{2}\right.$ y $\left.\mathrm{P}_{2} \mathrm{O}_{5}\right)$ se aprecian tendencias negativas muy claras con respecto al contenido de $\mathrm{SiO}_{2}$ (Figura 11). $\mathrm{El} \mathrm{Al}_{2} \mathrm{O}_{3}$ también muestra una correlación negativa, pero con una inflexión muy clara en contenidos aproximadamente a $64 \%$ en peso de $\mathrm{SiO}_{2}$. Dicha inflexión también es notoria en los otros elementos con correlación negativa.

Por otro lado, los elementos de tierras raras muestran ciertas diferencias dependiendo de la composición (Figura 12a y 12c). Por ejemplo, las unidades Andesítico-Basáltica y Andesítica presentan un enriquecimiento en tierras raras ligeras con respecto a las pesadas, con una ligera anomalía en Eu (Figura 12a). Resalta la muestra AZF-0881 (de la estructura El Capulín; Tabla 1) con valores más altos en casi todas las tierras raras, con una anomalía negativa en Ce y una marcada anomalía positiva en $\mathrm{Tb}$ (Figura 12a). El comportamiento anómalo de esta muestra puede deberse a procesos de meteorización (Patino et al., 2003). Las unidades Dacítica y Riolítica presentan la misma pendiente que las unidades máficas, pero resalta su mayor concentración en tierras raras ligeras, así como la anomalía negativa muy marcada en Eu para las Riolitas Yerbabuena y menos marcada para las Riolitas Agua Fría y Unidad Dacítica (Figura 12c). Para estas unidades félsicas también resalta la anomalía en $\mathrm{Tb}$, mucho más marcada para la subunidad Riolitas Yerbabuena. Valores relativamente altos en $\mathrm{Tb}$ (1.1 a 1.8 ppm; ver Tabla 1) para la Unidad Riolítica no son comunes en rocas ígneas, sin embargo existen ejemplos en rocas volcánicas de otras partes del mundo con valores similares o incluso mayores de hasta $2.68 \mathrm{ppm}$ en rocas del centro-sur de Italia (Avanzinelli et al., 2008). Este valor alto puede deberse a la presencia de minerales accesorios como la alanita que contiene una alta concentración en Tb con un coeficiente de partición muy alto (Spürgin et al., 2009). Sobre este punto, es pertinente mencionar que se ha reportado alanita como mineral accesorio en las riolitas del volcán Guangoche, el cual es parte de la subunidad Yerbabuena (Rangel, 2013, 2019; Rangel et al., 2018).

Los elementos traza normalizados con el manto primitivo, en todas las muestras despliegan pendientes similares (Figura 12b y 12d). Sin embargo, es posible observar diferencias particulares, en especial cuando se agrupan las unidades en: andesitas basálticas y andesitas, y en dacitas y riolitas. Las unidades Andesítico-Basáltica y Andesítica despliegan un enriquecimiento relativo en elementos incompatibles comparado con los elementos compatibles, con claras anomalías negativas de $\mathrm{Nb}$ y Ta, así como marcadas anomalías positivas en $\mathrm{Pb}$ y $\mathrm{K}$ (Figura 12b). Mientras que para las unidades Dacítica y Riolítica difieren de las unidades anteriores por las marcadas anomalías negativas en $\mathrm{Sr}, \mathrm{P}, \mathrm{Eu}$ y Ti, en particular para la subunidad Yerbabuena, mientras que para la subunidad Agua Fría la anomalía negativa de estos elementos es menos marcada. Así mismo, resalta la anomalía positiva en Th y U para la Unidad Riolítica (Figura 12d). Por último, destaca la anomalía negativa de Ba para algunas muestras de la subunidad Yerbabuena.

\section{DISCUSIÓN}

\section{Evolución de los magmas del CVLA}

La variación química de las rocas que componen al CVLA es muy amplia, de 54.2 a $76.4 \%$ en peso de $\mathrm{SiO}_{2}$ (Tabla 1; Figura 10). Las rocas riolíticas son las que cubren una mayor área en el mapa del CVLA (Figura 3), probablemente porque representan los productos más recientes y cubren a las otras unidades.

Todas las rocas muestran rasgos químicos asociados a un ambiente de subducción, con relativo enriquecimiento en tierras raras ligeras, así como en elementos incompatibles (Figura 12), con anomalías negativas muy marcadas en elementos inmóviles por fluidos acuosos 
como el $\mathrm{Nb}$, Ta y Ti, y anomalías positivas en $\mathrm{Pb}$ y U (Pearce et al., 2005), mientras que el Th está más enriquecido en las dacitas y riolitas. Este comportamiento aplica tanto para las rocas más máficas como para las rocas más evolucionadas, aunque en el caso de las riolitas, además se observan anomalías negativas pronunciadas de $\mathrm{Ba}, \mathrm{Sr}, \mathrm{P}$ y Eu, así como una anomalía negativa mucho más marcada en Ti, lo cual puede deberse a procesos de fraccionamiento de algunas fases minerales que incorporan estos elementos como es el caso de feldespato potásico, apatito e ilmenita (Baitis y Lindstrom, 1980; Nekvasil et al., 2000). Adicionalmente, al menos para las rocas ácidas, se aprecia un relativo enriquecimiento de Ta comparado con Nb (Figura 12d), que puede ser el resultado del fraccionamiento de biotita (Stepanov y Hermann, 2013).

La Unidad Andesítico-Basáltica en general tiene valores relativamente altos en $\mathrm{Mg \#} \mathrm{(>60;} \mathrm{Tabla} \mathrm{1),} \mathrm{que} \mathrm{junto} \mathrm{con} \mathrm{la} \mathrm{presencia} \mathrm{de}$ olivino, sugiere que se trata de magmas relativamente primitivos. Sin embargo, es probable que los magmas asociados a esta unidad hayan sufrido en alguna medida procesos de evolución magmática, dado que algunas muestras presentan valores bajos de $\mathrm{Mg \#} \mathrm{(51} \mathrm{y} \mathrm{47)} \mathrm{y} \mathrm{bajos}$ contenidos en Ni (86 a 35 ppm; Tabla 1). Por su parte, las muestras de la Unidad Andesítica tienen valores de Mg\# entre 61 y 41, las dacitas entre 45 y 33 y por último las riolitas entre 26 y 8 (Tabla 1), lo que podría indicar que todas las unidades al parecer han sufrido procesos de evolución (Kirstein et al., 2000), desde las más primitivas (andesita basáltica) hasta las más félsicas (riolitas).

Las tendencias que muestran los diagramas binarios de elementos mayores están bien definidas, a excepción del $\mathrm{Na}_{2} \mathrm{O}$ (Figura 11), lo que sugieren una misma fuente parental, y es un reflejo del fraccionamiento de minerales máficos como olivino, piroxeno, plagioclasa cálcica, anfíbol y magnetita que pueden generar un descenso en los contenidos de $\mathrm{Fe}_{2} \mathrm{O}_{3}, \mathrm{MgO}, \mathrm{CaO}, \mathrm{Al}_{2} \mathrm{O}_{3}$ y $\mathrm{TiO}_{2}$ y enriquecimiento relativo de $\mathrm{K}_{2} \mathrm{O}$ (Wilson, 1989). El quiebre en la pendiente que se aprecia en la mayoría de los elementos en los diagramas binarios de la Figura 11, puede reflejar un cambio en la proporción y/o tipo de fases que fraccionan, por ejemplo, para el $\mathrm{MgO}$ y $\mathrm{Fe}_{2} \mathrm{O}_{3}$ el quiebre ubicado a aproximadamente $64 \%$ en peso de $\mathrm{SiO}_{2}$, puede ser producto del fraccionamiento de anfíbol y plagioclasa, ya que coincide con el cambio a una mayor pendiente para el $\mathrm{Al}_{2} \mathrm{O}_{3}$ (Baitis y Lindstrom, 1980).

Sin embargo, para el caso de los elementos traza las correlaciones no son tan claras, lo que sugiere que no solo el proceso de cristalización fraccionada es responsable de la variación en el contenido de estos elementos. Por ejemplo, las relaciones $\mathrm{Th} / \mathrm{Nb}$ (Figura 13a) muestran un incremento sistemático (de 0.2 hasta 1.2) con el aumento en $\mathrm{SiO}_{2}$, muy por encima de los valores para el MORB $(\mathrm{Th} / \mathrm{Nb}=0.04-0.07)$, lo que sugiere un aporte de Th (así como de U), desde otra fuente, ya sea por mezcla de magmas o contaminación cortical (Kirstein et al., 2000). Al respecto, es importante resaltar el hecho de que las relaciones $\mathrm{Th} / \mathrm{Nb}$ de algunas rocas intrusivas del área de La Huacana, Michoacán (OrtegaGutiérrez et al., 2014; Corona-Chávez et al., 2006; Rasoazanamparany et al., 2016) muestran valores similares a los productos riolíticos del CVLA (Figura 13a).

Los plutones de La Huacana ubicados aproximadamente a $150 \mathrm{~km}$ al SO del CVLA, en el estado de Michoacán (Figura 1), han sido descritos y muestreados en la localidad del mismo nombre (Tabla 1). Estos intrusivos están conformados por granitos, granodioritas, dioritas, tonalitas y cuarzomonzonitas y han sido fechados por el método $\mathrm{Rb} / \mathrm{Sr}$ en $42 \mathrm{Ma}$ (Schaaf et al., 1995) y por el método ${ }^{40} \mathrm{Ar} /{ }^{39} \mathrm{Ar}$ en plagioclasa en $34 \mathrm{Ma}$ (Martini et al., 2009) ubicándolos en el Eoceno medio-tardío (Figura 2). Cabe destacar que se han reportado xenolitos granodioríticos, dioríticos, graníticos y cuarzomonzoníticos en rocas de los volcanes Jorullo, Parícutin y Arócutin (del CVMG), que han sido asociados con los intrusivos de La Huacana (McBirney et al., 1987; Corona-Chavez et al., 2006; Rasoazanamparany et al., 2016), por lo tanto, es muy probable que los denominados plutones de La Huacana también estén por debajo del Campo Volcánico de Los Azufres.

Con el propósito de definir el o los procesos involucrados en la evolución de los magmas que dieron origen al CVLA (desde andesitas basálticas a riolitas), se desarrolló un modelo petrogenético donde se consideraron los siguientes parámetros: como magma inicial se consideró a la muestra TP-1406 (Tabla 1) que representa una de las más máficas de la Unidad Andesítico-Basáltica, como asimilante se tomó una diorita de La Huacana (muestra MG-0551; Ortega-
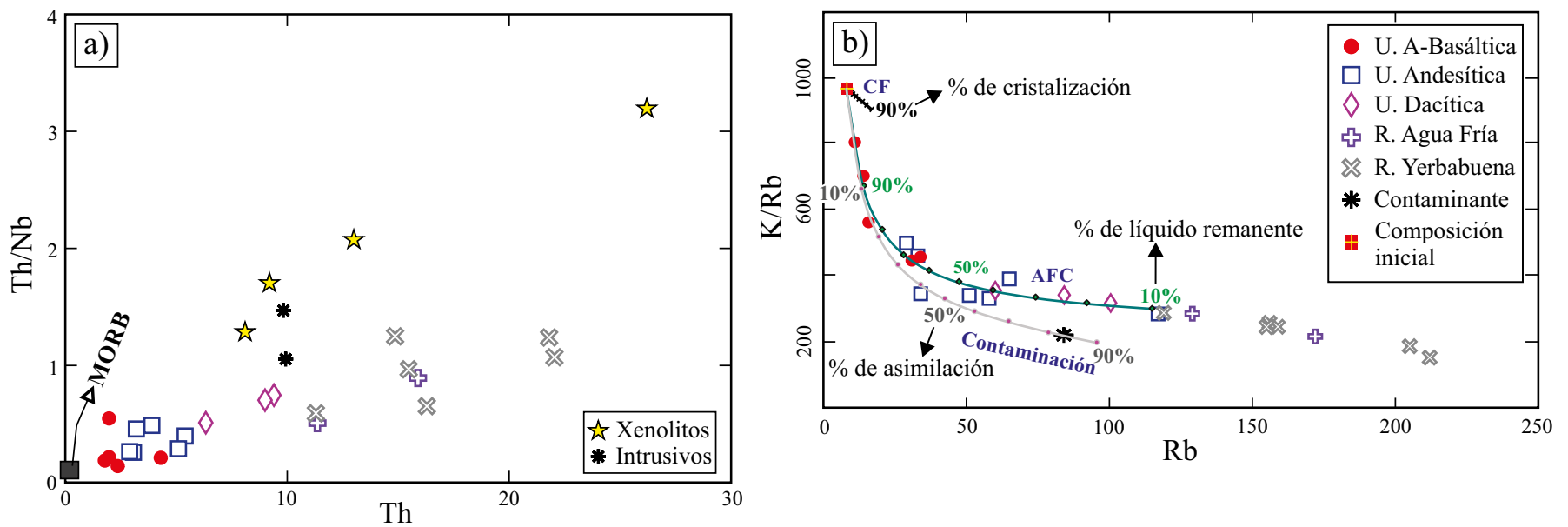

Figura 13. a) Th versus Th/Nb para muestras del Campo Volcánico de Los Azufres (CVLA). Datos del MORB (Sun y McDonough, 1989), rocas intrusivas dioríticas de La Huacana (Ortega-Gutiérrez et al., 2014) y xenolitos dioríticos, granodioríticos y graníticos reportados en los volcanes Jorullo (Rasoazanamparany et al., 2016) y Arócutin (Corona-Chávez et al., 2006). b) Modelos petrogenéticos de cristalización fraccionada (CF), asimilación combinada con cristalización fraccionada (AFC) y contaminación cortical sin cristalización fraccionada, para explicar la evolución magmática de las rocas del CVLA. Se consideró como magma inicial la muestra TP-1406 de la Unidad Andesítico-Basáltica, como contaminante a un intrusivo diorítico de La Huacana (muestra MG-0551), asumiendo un índice de cristalización del $54 \%$, un coeficiente de tasa asimilada/tasa cristalizada (r) de 0.5 , con la cristalización de olivino (5\%), piroxeno (15\%), plagioclasa (10 \%) y feldespato potásico (5\%). El modelo de AFC es el que mejor se ajusta a las muestras máficas, pero no reproduce las muestras más riolíticas. La contaminación cortical también se ajusta a algunas muestras máficas, pero en menor medida. 
Gutiérrez et al., 2014), se asumió un factor de $r$ (tasa de asimilación/ cristalización) de 0.5 (Figura 13b) con un $54 \%$ de cristalización del líquido inicial. Con base en las consideraciones anteriores, para este caso, la simulación que mejor se ajustó a los datos químicos de las muestras del CVLA fue el modelo de AFC (asimilación combinada con cristalización fraccionada; De Paolo, 1981), considerando los siguientes porcentajes de fraccionamiento: $5 \%$ de olivino, $15 \%$ de piroxeno, $10 \%$ de plagioclasa y $5 \%$ de feldespato potásico. Sin embargo, es importante señalar que en menor medida, la línea de contaminación cortical simple (es decir sin involucrar cristalización fraccionada de alguna fase mineral) se ajusta a algunas muestras andesítico basálticas y andesíticas (Figura 13b). No obstante, las evidencias muestran que el principal mecanismo responsable de la evolución de los fundidos andesíticos y dacíticos es la asimilación-cristalización fraccionada. Aunque también debe mencionarse, que la línea de AFC también sólo se ajusta de manera clara a las muestras andesítico basálticas, andesíticas, dacíticas y algunas riolitas.

Por tanto, es claro que los procesos de AFC, asimilación pura y cristalización fraccionada no explican las tendencias generadas por las riolitas (tanto Agua Fría como Yerbabuena), al menos usando al granito de La Huacana como contaminante, debido a que las riolitas tienen mayor contenido de $\mathrm{Rb}$ que el contaminante, por lo que podría indicar que otro mecanismo sería el responsable de la génesis de estos magmas muy evolucionados. Al respecto, es probable que la génesis de estos últimos magmas, esté asociado a fundidos andesíticos o dacíticos, con contribución de rocas de la corteza, dado el enriquecimiento en Th y U (Figuras 12 y 13).

Para las rocas de la Unidad Dacítica, y a pesar de que no se realizaron análisis de química mineral, las evidencias petrográficas como la presencia de enclaves máficos, poblaciones de fenocristales de plagioclasa afectadas por disolución, textura de tamiz y coronas de reacción en algunos cristales de biotita (ver sección de resultados), podrían apuntar a la mezcla de magmas como proceso adicional en la evolución de los fundidos dacíticos. Estas características fueron observadas en las muestras del estratovolcán San Andrés (Macías et al., 2008), por lo que es probable que procesos de mezcla de magmas hayan tenido lugar en su cámara magmática para producir magmas dacíticos.

Por último, para los magmas riolíticos del CVLA se ha propuesto el mecanismo de extracción de fundido a partir de un mush cristalino para la generación de los magmas riolíticos del volcán Guangoche (subunidad Riolitas Yerbabuena; Rangel et al., 2018; Rangel, 2019). Un mush cristalino se refiere a un cuerpo magmático silícico que se encuentra a profundidad, con $>60 \%$ de cristales (Hildreth, 2004; Streck, 2014; Bachmann y Huber, 2016) y episódicamente afectado por inyecciones de magmas más profundos. Dichas inyecciones pueden generar la segregación y eventualmente la extracción del líquido residual y generar erupciones volcánicas efusivas o explosivas, dando lugar a rocas pobres en cristales, muy silícicas y con anomalías pronunciadas en Eu, Sr y Ba (Bachmann y Bergantz, 2004, 2008; Streck, 2014). Profundizar sobre las características de un mush cristalino está fuera de los alcances de la presente investigación, sin embargo, es indispensable realizar estudios específicamente sobre la génesis de las riolitas del CVLA y explorar otras posibilidades en cuanto a mecanismos de evolución magmática, usando mayor cantidad de datos geoquímicos e isotópicos, en especial de $\mathrm{Sr}, \mathrm{Nd}$ y $\mathrm{Pb}$ para dar mayor certidumbre a esta hipótesis. Los resultados de este trabajo sin duda son un primer paso en la dirección para tratar de explicar los procesos involucrados en la evolución magmática que dio origen a la heterogeneidad química del CVLA, donde los mecanismos de AFC y contaminación explican en buena medida las tendencias evolutivas de los magmas composicionalmente diversos de este campo volcánico.

\section{CONCLUSIONES}

Elvulcanismo en el Campo Volcánico Los Azufres inició hace 1.57 Ma, con actividad reciente de $<26 \mathrm{ka}$. Los productos volcánicos muestran una gran diversidad composicional, desde andesitas basálticas hasta riolitas, con el desarrollo de diversas estructuras volcánicas como flujos de lava en forma de mesas, domos y estratovolcanes (Guangoche y San Andrés), muchos de éstos con la generación de depósitos piroclásticos de composición ácida. Los elementos mayores despliegan correlaciones negativas bien definidas en $\mathrm{MgO}, \mathrm{Fe}_{2} \mathrm{O}_{3}, \mathrm{CaO}, \mathrm{TiO}_{2}$ y $\mathrm{P}_{2} \mathrm{O}_{5}$, así como una correlación positiva en $\mathrm{K}_{2} \mathrm{O}$, que sugieren el fraccionamiento de minerales máficos. De manera general, la mayoría de las tendencias generadas por los datos químicos muestran un cambio en la pendiente, reflejo de un cambio en el ensamble mineral que fracciona, que para el caso del $\mathrm{Al}_{2} \mathrm{O}_{3}$ puede representar un fraccionamiento importante de plagioclasa y anfíbol al alcanzar contenidos de $64 \%$ en peso de $\mathrm{SiO}_{2}$.

El modelo petrogenético de elementos traza mostró que, tomando una muestra de la Unidad Andesítico-Basáltica como magma inicial, al intrusivo de La Huacana como contaminante, y asumiendo la cristalización de olivino, piroxeno, plagioclasa y feldespato-K, se concluye que el principal mecanismo de evolución magmática en el CVLA fue el de asimilación acoplada con cristalización fraccionada (AFC), y en menor medida fue producto de contaminación cortical sin cristalización fraccionada.

En particular, para el caso de los magmas de la Unidad Dacítica también se debe tomar en cuenta el mecanismo de mezcla de magmas como responsable de su evolución. Mientras que para los productos riolíticos existe otro mecanismo que parece estar incidiendo en el proceso de evolución magmática, generando una tendencia que no se explica con nuestro modelo de AFC, por lo que es posible que corresponda con algún otro proceso de evolución.

\section{AGRADECIMIENTOS}

Este trabajo representa un resultado directo del convenio CFEUNAM \#9400035204, para el estudio vulcanológico del campo geotérmico de Los Azufres, Michoacán, con el apoyo de la Gerencia de Proyectos Geotermoeléctricos de CFE, Morelia. En particular se agradece el invaluable apoyo del Ing. Héctor Pérez Esquivias (CFE) por las facilidades para el desarrollo del proyecto mencionado y por compartir su conocimiento sobre el campo geotérmico de Los Azufres. Así mismo, agradecemos al Dr. Víctor Hugo Garduño (†) por las discusiones durante el trabajo de campo. Se agradece al proyecto PAPIIT IN101620 (JL Arce) por el financiamiento parcial a esta investigación. Gracias a M.C. Macías-Romo por el apoyo en la preparación de muestras para los distintos análisis. Algunos análisis químicos por FRX fueron realizados por la Quim. Patricia Girón y por ICP-MS por la M. en C. Ofelia Pérez. Un agradecimiento especial a la Dra. Teresa Orozco y un revisor anónimo, quienes con sus sugerencias y comentarios enriquecieron de manera sustancial la versión final del manuscrito. Así mismo, se agradece el manejo editorial por parte de los Drs. I. Israde y J.L. Macías.

\section{REFERENCIAS}

Aguirre-Díaz, G.J., 2003, Características generales del Cinturón Volcánico Mexicano. Una revisión por sectores: Unión Geofísica Mexicana, Geos, 23(2), 118-119.

Aguirre-Díaz, G., López-Martínez, M., 2001, The Amazcala caldera, Querétaro, 
México. Geology and geochronology: Journal of Volcanology and Geothermal Research, 111, 203-218.

Altamira-Areyán, A., 2002, Las litofacies y sus implicaciones de la cuenca sedimentaria Cutzamala-Tiquicheo, Estados de Guerrero y Michoacán, México: Ciudad de México, México, Universidad Nacional Autónoma de México, Tesis de Maestría, 79 pp.

Arce, J.L., Macías, J.L., Rangel, E., Layer, P., Garduño-Monroy, V.H., Saucedo, R., García, F., Castro, R., Pérez- Esquivias, H., 2012, Late Pleistocene rhyolitic explosive volcanism at Los Azufres Volcanic Field, central Mexico, en Aranda-Gómez, J.J., Tolson, G., Molina-Garza, R.S. (eds.), The Southern Cordillera and Beyond: Geological Society of America, Field Guide, 25, 45-82.

Aumento, F., Gutiérrez, A., 1980, Geocronología de Los Azufres, Michoacán: Morelia, Mich., México, Comisión Federal de Electricidad, reporte interno, $6 \mathrm{pp}$.

Avanzinelli, R., Elliott, T., Tommasini, S., Conticelli, S., 2008, Constraints on the genesis of potassium-rich italian volcanic rocks from U/Th Disequilibrium: Journal of Petrology, 49, 195-223.

Bachmann, O., Bergantz, G.W., 2004, On the origin of crystal-poor rhyolites: extracted from batholithic crystal mushes: Journal of Petrology, 45, 1565-1582.

Bachmann, O., Bergantz, G.W., 2008, Rhyolites and their source mushes across tectonic settings: Journal of Petrology, 49, 2277-2285.

Bachmann, O., Huber, C., 2016, Silicic magma reservoirs in the Earth's crust: American Mineralogist, 101, 2377-2404.

Baitis, H.W., Lindstrom, M.M., 1980, Geology, petrography, and petrology of Pinzon Island, Galapagos Archipelago: Contributions to Mineralogy and Petrology, 72, 367-386.

Benammi, M., Centeno-García, E., Martínez-Hernández, E., Morales-Gámez, M., Tolson, G., Urrutia-Fucugauchi, J., 2005, Presencia de dinosaurios en la Barranca Los Bonetes en el sur de México (Región de Tiquicheo, Estado de Michoacán) y sus implicaciones cronoestratigráficas: Revista Mexicana de Ciencias Geológicas, 22, 429-435.

Camacho, F., 1979, Geología de la zona geotérmica de Los Azufres, Michoacán: Morelia, Mich., México, Comisión Federal de Electricidad, reporte interno, $18 \mathrm{pp}$.

Camacho, F., Palacios, N.M., 1979, Geología de la zona geotérmica de Los Azufres, Michoacán: Morelia, Mich., México, Comisión Federal de Electricidad, reporte interno, $42 \mathrm{pp}$.

Campos-Enríquez, J.O., Garduño-Monroy, V.H., 1995, Los Azufres silicic center (Mexico): inference of caldera structural elements from gravity, aeromagnetic, and geoelectric data: Journal of Volcanology and Geothermal Research, 67, 123-152.

Cathelineau, M., Oliver-Hermandez, R., Nieva-Gómez, D., 1987, Geochemistry of volcanic series of the Los Azufres geothermal field (Mexico): Geofísica Internacional, 26, 273- 290.

Cathelineau, M., Izquierdo, G., Vázquez, G.R., Guevara, M., 1991, Deep geothermal wells in the Los Azufres (Mexico) caldera: Volcanic basement stratigraphy based on major- element analysis. Journal of Volcanology and Geothermal Research, 47, 149-159:

CeMIEGeo (Centro Mexicano de Innovación en Energía Geotérmica), 2018, Geotermia en México, disponible en http://www.cemiegeo.org/index.php/ geotermia-en-mexico, consultado: 20 de mayo, 2021.

Centeno-García, E., Guerrero-Suastegui, M., Talavera-Mendoza, O., 2008, The Guerrero Composite Terrane of western Mexico: Collision and subsequent rifting in a supra- subduction zone, en Draut, A., Clift, P.D., Scholl, D.W. (eds.), Formation and Applications of the Sedimentary Record in Arc Collision Zones: The Geological Society of America, Special Paper, 436, 279-308.

Corona-Chávez, P., Reyes-Salas, M., Garduño-Monroy, V.H., Israde-Alcántara, I., Lozano- Santacruz, R., Morton-Bermea, O., Hernández-Alvarez, E., 2006, Asimilación de xenolitos graníticos en el Campo Volcánico Michoacán-Guanajuato: El caso de Arócutin Michoacán, México: Revista Mexicana de Ciencias Geológicas, 23, 233-245.

De la Cruz, V., Aguilar, J., Ortega, D., Sandoval, J.M., 1982, Estudio geológico estructural a detalle del campo geotérmico de Los Azufres, Michoacán: Morelia, Mich., México, Comisión Federal de Electricidad, reporte interno, $41 \mathrm{pp}$.

Demant, A., 1978, Características del Eje Neovolcánico Transmexicano y sus problemas de interpretación: Universidad Nacional Autónoma de México,
Revista del Instituto de Geología, 2, 172-187.

Demant, A., 1981, Interpretación geodinámica del volcanismo del Eje Neovolcánico Transmexicano: Universidad Nacional Autónoma de México, Revista del Instituto de Geología, 5, 217-222.

Demant, A., Mauvois, R., Silva-Mora, L., 1975, Estudio geológico de las hojas Morelia- Maravatio (1/100000), estado de Michoacán: Ciudad de México, México, Instituto de Geología, Universidad Nacional Autónoma de México, reporte interno, $40 \mathrm{pp}$.

DePaolo, D.J., 1981, Trace element and isotopic effects of combined wallrock assimilation and fractional crystallization. Earth and Planetary Science Letters, 53, 189-202.

Dobson, P.F., Mahood, G.A., 1985, Volcanic stratigraphy of the Los Azufres geothermal area, Mexico: Journal of Volcanology and Geothermal Research, 25, 273-287.

Ferrari, L., Garduño, V.H., Pasquaré, G., Tibaldi, A., 1991, Geology of Los Azufres caldera, Mexico, and its relationships with regional tectonics: Journal of Volcanology and Geothermal Research, 47, 129-148.

Ferrari, L., López-Martínez, M., Aguirre-Díaz, G., Carrasco-Nuñez, G., 1999, Space-time patterns of Cenozoic arc volcanism in central Mexico: From Sierra Madre Occidental to the Mexican Volcanic Belt: Geology, 27, 303-306.

Ferrari, L., Orozco-Esquivel, T., Manea, V., Manea, M., 2012, The dynamic history of the Trans-Mexican Volcanic Belt and the Mexico subduction zone: Tectonophysics, 522- 523, 122-149.

Fowler, S.J., Bohrson, W.A., Spera, F.J., 2004, Magmatic evolution of the Skye Igneous Centre, western Scotland: Modelling of assimilation, recharge and fractional crystallization: Journal of Petrology, 45, 2481-2505.

Garduño-Monroy, V.H., 1987, Estudio geológico regional para conocer las características de las rocas del basamento relativo del campo geotérmico de los Azufres: Morelia, Mich., México, Comisión Federal de Electricidad, reporte interno, $73 \mathrm{pp}$.

Garduño-Monroy, V.H., Martiñón-García, H., 1984, Análisis estructural de la zona sur del campo geotérmico de Los Azufres, Michoacán: Morelia, Mich., México, Comisión Federal de Electricidad, reporte interno, 179 pp.

Garfias, A., González, A., 1978, Resultados de las exploraciones en la zona geotérmica de Los Azufres, Michoacán, México: Morelia, Mich., México, Comisión Federal de Electricidad, reporte interno, 42 pp.

Gómez-Tuena, A., Orozco-Esquivel, M.T, Ferrari, L., 2005, Petrogénesis ígnea de la Faja Volcánica Transmexicana: Boletín de la Sociedad Geológica Mexicana, 57, 227-283.

Gómez-Vasconcelos, M.G., Garduño-Monroy, V.H., Macías, J.L., Layer, P.W., Benowitz, J.A., 2015, The Sierra de Mil Cumbres, Michoacán, México: Transitional volcanism between the Sierra Madre Occidental and the Trans-Mexican Volcanic Belt: Journal of Volcanology and Geothermal Research, 301, 128-147.

Gómez-Vasconcelos, M.G., Macías, J.L., Avellán D.R., Sosa-Ceballos, G., Garduño-Monroy, G.M., Cisnero-Máximo, G., Layer, P.W., Benowitz J., López-Loera, H., Mendiola- López, F., Perton, M., 2020, The control of pre-existing faults on the distribution, morphology, and volume of monogenetic volcanism in the Michoacán-Guanajuato Volcanic Field: Geological Society of America Bulletin, 132, 2455.-2474.

Hildreth, W., 2004, Volcanological perspective on Long Valley, Mammoth Mountain, and Mono Craters: several contiguous but discrete systems: Journal of Volcanology and Geothermal Research, 136, 169-198.

Israde-Alcantara, I., Garduño-Monroy, V.H., 1999, Lacustrine record in a volcanic intra-arc setting: the evolution of the Late Neogene Cuitzeo basin system (central-western Mexico, Michoacán): Palaeogeography, Palaeoclimatology, Palaeoecology, 151, 209-227.

Israde-Alcántara, I., Robles-Camacho, J., Domínguez, J.M., 2008, Arcillas del tipo beidellita-nontronita en sedimentos neógenos de la cuenca lacustre Cuitzeo- Charo, Michoacán, México: Contexto geológico e implicaciones paleoambientales: Boletín de la Sociedad Geológica Mexicana, 60, 159-171.

Israde-Alcántara, I., Miller, W., Garduño-Monroy, V., Barron, J., RodríguezPascua, M., 2010, Palaeoenvironmental significance of diatom and vertebrate fossils from Late Cenozoic tectonic basins in west- central México: A review: Quaternary International, 219, 79-94

Kirstein, L.A., Peate, D.W., Hawkesworth, C.J., Turner, S.P., Harris, C., Mantovani, M.S.M., 2000, Early Cretaceous basaltic and rhyolitic magmatism in southern Uruguay associated with the opening of the South Atlantic: Journal of Petrology, 41, 1413-1438. 
Le Bas, M.J., Le Maitre, R.W., Streckeisen, A., Zanettin, B., 1986, A chemical classification of volcanic rocks based on the total alkali-silica diagram: Journal of Petrology, 27, 745- 750.

Lozano-Santa Cruz, R., Bernal, J.P., 2005, Characterization of a new set of eight geochemical reference materials for XRF major and trace elements analysis: Revista Mexicana de Ciencias Geológicas, 14, 329-359.

Lozano-Santa Cruz, R., Verma, S.P., Girón, P., Velasco, F., Morán-Zenteno, D., Viera, F., Chávez, G., 1995, Calibración preliminar de fluorescencia de rayos $\mathrm{X}$ para análisis cuantitativo de elementos mayores en rocas ígneas: Actas INAGEQ, 1, 203-208.

Macías, J.L., Arce, J.L., Garduño, V.H., Castro, R., García-Tenorio, F., Saucedo, R., 2008, Estudio vulcanológico y estructural de la secuencia estratigráfica Mil Cumbres y la zona geotérmica de los Azufres, Michoacán: Morelia, Mich., México, Comisión Federal de Electricidad, reporte interno, 73 pp.

Mariscal-Ramos, C., Talavera-Mendoza, O., Centeno-García, E., MoralesGámez, M., Benammi, M., 2005, Preliminary magnetostratigraphic study of the Upper Cretaceous dinosaur site from La Barranca Los Bonites, Tiquicheo (Michoacán State, Southern Mexico), en Reunión Anual de la Unión Geofísica Mexicana: Puerto Vallarta, México, GEOS, 25: 57-58.

Martini, M., Ferrari, L., López-Martínez, M., Cerca-Martínez, M., Valencia, V.A., Serrano- Durán, L., 2009, Cretaceous-Eocene magmatism and Laramide deformation in southwestern Mexico: No role for terrane accretion, en Kay, S.M., Ramos, V.A., Dickinson, W.R. (eds.), Backbone of the Americas: Shallow Subduction, Plateau Uplift, and Ridge and Terrane Collision: Geological Society of America Memoir, 204, 151-182.

McBirney, A.R., Taylor, H.P., Armstrong, R.L., 1987, Paricutin re-examined: a classic example of crustal assimilation in calc-alkaline magma: Contributions to Mineralogy and Petrology, 95, 4-20.

Mori, L., Gómez-Tuena, A., Cai, Y., Goldstein, S.L., 2007, Effects of prolonged flat subduction on the Miocene magmatic record of the central TransMexican Volcanic Belt: Chemical Geology, 244, 452-473.

Nekvasil, H., Simon, A., Lindsley, D.H., 2000, Crystal fractionation and the evolution of intra-plate hy-normative igneous suites: Insights from their feldspars: Journal of Petrology, 41, 1743-1757.

Ortega-Gutiérrez, F., Gómez-Tuena, A., Elías-Herrera, M., Solari, L.A., ReyesSalas, M., Macías-Romo, M.C., 2014, Petrology and geochemistry of the Valle de Santiago lower-crust xenoliths: Young tectonothermal processes beneath the central Trans- Mexican volcanic belt: Lithosphere, 6, 335-360.

Palacios, N.M., Camacho, F., 1976, Informe geológico de la zona geotérmica de Los Azufres, Michoacán: Morelia, Mich., México, Comisión Federal de Electricidad, reporte interno, $18 \mathrm{pp}$.

Pardo, M., Suárez, G., 1995, Shape of the subducted Rivera and Cocos plates in southern Mexico: seismic and tectonic implications: Journal of Geophysical Research, 100, 12357-12373.

Pasquaré, G., Ferrari, L., Garduño, V., Tibaldi, A., Vezzoli, L., 1991, Geologic map of the central sector of the Mexican Volcanic Belt, states of Guanajuato and Michoacán, Mexico: Geological Society of America, Maps and Charts Series MCH072.

Patino, L.C., Velbel, M.A., Price, J.R., Wade, J.A., 2003, Trace element mobility during spheroidal weathering of basalts and andesites in Hawaii and Guatemala: Chemical Geology, 202, 343-364.

Pearce, J.A., Stern, R.J., Bloomer, S.H., Fryer, P., 2005, Geochemical mapping of the Mariana arc-basin system: implications for the nature and distribution of subduction components: Geochemistry, Geophysics and Geosystems, 6(7), doi:10.1029/2004GC000895

Pérez-Esquivias, H., Macías-Vásquez, J.L., Garduño-Monroy, V.H., ArceSaldaña, J.L., García-Tenorio, F., Castro-Govea, R., Layer, P., SaucedoGirón, R., Martínez, C., Jiménez-Haro, A., Valdés, G., Meriggi, L., Hernández, R., 2010, Estudio vulcanológico y estructural de la secuencia estratigráfica Mil Cumbres y del campo geotérmico de Los Azufres, Michoacán: Geotermia, 23, 51-63.
Pradal, E., 1990, La caldera de Los Azufres (Mexique): Contexte volcanologique d'un grand champ géothermique: Clermont-Ferrand, Francia, Universidad de Clermont-Ferrand, Tesis de Doctorado, $246 \mathrm{pp}$.

Pradal, E., Robin, C., 1985, Découverte d'une caldera majeure associée au champ géothermique Los Azufres (Mexique): Comptes Rendus de l'Académie des Sciences Paris, 301, 1069-1074.

Pradal, E., Robin, C., 1994, Long-lived magmatic phases at Los Azufres volcanic center, Mexico: Journal of Volcanology and Geothermal Research, 63, 201-215.

Rangel, E., 2013, Volcán Guangoche, Campo Volcánico Los Azufres, Michoacán, México: Estratigrafía y parámetros físicos de erupciones SubplinianasPlinianas del Pleistoceno tardío: Ciudad de México, México, Universidad Nacional Autónoma de México, Tesis de Maestría, 173 pp.

Rangel, E., 2019, Origen y condiciones pre eruptivas de magmas riolíticos del volcán Guangoche, Campo Volcánico Los Azufres, Michoacán: Ciudad de México, México, Universidad Nacional Autónoma de México, Tesis de Doctorado, 168 pp.

Rangel, E., Arce, J.L., Macías, J.L., 2018, Storage conditions of the rhyolitic Guangoche White Pumice Sequence, Los Azufres Volcanic Field, Central Mexico: Journal of Volcanology and Geothermal Research, 358, 132-148.

Rasoazanamparany, C., Widom, E., Siebe, C., Guilbaud, M.-N., Spicuzza, M.J., Valley, J.W., Valdez, G., Salinas, S., 2016, Temporal and compositionl evolution of Jorullo volcano, Mexico: Implications for magmatic processes associated with a monogenetic eruption: Chemical Geology, 434, 62-80.

Schaaf, P., Morán-Zenteno, D.J., Hernández-Bernal, M.S., Solís-Pichardo, G., Tolson, G., Kohler, H., 1995, Paleogene continental margin truncation in south-western Mexico: Geochronological evidence: Tectonics, 14, 1339-1350.

Silva-Mora, L., 1979, Contribution a la connaissance de l'Axe volcanique Transmexican: étude géologique et pétrologie des lavas du Michoacán oriental: Marsella, Francia, Université de Aix-Marseille, III, Tesis de tercer ciclo, 146 pp.

Spürgin, S., Selbekk, R.S., Lundmark, A.M., 2009, Mineralogy and geological setting of allanite-(Ce)-pegmatites in western Hurrungane, Jotun Nappe Complex, Norway: an EMP and IF-TIMS study: Norwegian Journal of Geology, 89, 341-356.

Stepanov, A.S., Hermann, J., 2013, Fractionation of $\mathrm{Nb}$ and $\mathrm{Ta}$ by biotite and phengite: Implications for the "missing Nb paradox": Geology, 41, 303-306.

Streck, M.J., 2014, Evaluation of crystal mush extraction models to explain crystal-poor rhyolites: Journal of Volcanology and Geothermal Research, 284, 79-94.

Sun, S.-s., McDonough, W.F., 1989, Chemical and isotopic systematics of oceanic basalts: implications for mantle composition and processes, en Saunders, A.D. Norry, M.J. (eds.), Magmatism in the ocean basins: Geological Society of London Special Publications, 42, 313-345.

Talavera-Mendoza, O., Ruiz, J., Gehrels, G.E., Valencia, V.A., Centeno-García, E., 2007, Detrital zircon U/Pb geochronology of southern Guerrero and western Mixteca arc successions (southern Mexico): New insights for the tectonic evolution of the southwestern North America during the late Mesozoic: Geological Society of America Bulletin, 119, 1052-1065.

Van der Plas, L., Tobi, A.C., 1965, A chart for judging the reliability of point counting results: American Journal of Science, 263, 87-90.

Wilson, B.M., 1989, Igneous Petrogenesis, a global tectonic approach: Dordrecht, The Netherlands, Springer, 457 pp.

Manuscrito recibido: marzo 11, 2021

Manuscrito corregido recibido: junio 22, 2021

Manuscrito aceptado: julio 2, 2021 